\title{
Determinantes del diferencial salarial por género en Colombia durante el periodo 2004 - 2012: Una aplicación de regresión por cuantiles
}

\author{
Camilo Fabiam Gómez Segura* \\ Tesis de Maestría \\ Maestría en Economía \\ Universidad Nacional de La Plata \\ Director de Tesis: Javier Alejo
}

\begin{abstract}
Resumen
El presente trabajo analiza los determinantes del diferencial salarial por género en Colombia durante el periodo 2004 - 2012, utilizando las encuestas empalmadas MESEP DANE en los años 2004, 2008 y 2012. Para ello se realiza la descomposición de la brecha salarial en los diferentes puntos de la distribución incondicional de los salarios. Los resultados obtenidos muestran que existe un diferencial salarial promedio en favor de los hombres y creciente en el tiempo, el cual se explica en $20 \%$ y $40 \%$ por factores diferentes a la productividad de los individuos. Así mismo, al analizar el diferencial salarial por género en los distintos cuantiles de la distribución del ingreso, se encuentra que el componente efecto remuneración explica principalmente la brecha bruta; no obstante es el componente efecto característica el que determina un incremento en el diferencial salarial a medida que avanzamos por la distribución de salarios, este resultado evidencia la existencia de un “Techo de Cristal” para las mujeres.

Clasificación JEL: J15, J16, J31, J70.
\end{abstract}

\footnotetext{
* Universidad Nacional de La Plata. Email: cafagose@hotmail.com. El autor agradece a Javier Alejo por su guía y apoyo durante todo el proceso de tesis, así mismo agradece los valiosos aportes de los participantes del seminario de avance de tesis. Los errores u omisiones son de totalidad responsabilidad del autor.
} 


\section{Introducción}

El ingreso laboral es uno de los componentes más importantes en el mercado laboral, siendo una variable que influye de manera directa en el bienestar individual. Sin embargo, el ingreso laboral depende de ciertas características tanto del individuo como del propio mercado laboral, lo cual hace que exista heterogeneidad en el salario. El problema surge cuando esta dispersión en el ingreso laboral esta explicada por características observables que en cierto modo no infieren productividad, como es el caso del género o la raza.

En Colombia el diferencial salarial por género ha sido decreciente en las últimas décadas, debido al incremento en la participación laboral ${ }^{1}$ (véase gráfica 1), la cual se puede explicar por grandes cambios o transformaciones sociales y culturales que han permitido a la mujer alcanzar mayor acceso al sistema educativo, incrementar su probabilidad de empleo, aumentar su experiencia laboral; en otras palabras las mujeres pasaron a complementar el mercado de trabajo (Florez, 2004). En los últimos 50 años la participación laboral de las mujeres en Colombia ha estado en aumento, pasando de $19 \%$ a $39 \%$ en el periodo 1950 1985, y a su vez presentando un incremento en la educación, como también una especie de movilidad hacia actividades económicas con mayores ingresos (Tenjo, 1993).

Este resultado se asemeja a los obtenidos por Urdinola (1998), el cual establece que durante el periodo 1982 - 1997 en Colombia para las siete principales ciudades del país, el género femenino tuvo una participación laboral del 36\% al 48\% respectivamente. La gráfica 2 muestra la tasa de global de participación laboral para último trimestre móvil en Colombia por género durante el periodo 2001 - 2013. Como se puede observar la tasa de participación laboral para hombres muestra un comportamiento estable en la última década. Por su parte, las mujeres muestran un incremento de $1,9 \%$ en su tasa global de participación, pasando de 50,5\% en el trimestre diciembre - febrero de 2003 a tener una participación del 59,9\% para el año 2013. No obstante, los resultados presentan una gran diferencia en la participación laboral a favor de los hombres, con una participación laboral de $75,4 \%$ para el trimestre diciembre - febrero de 2013, ocho puntos porcentuales por

\footnotetext{
${ }^{1}$ La tasa de participación laboral es el porcentaje de la población en edad de trabajar (PET) (Población mayor de 12 años), la cual es económicamente activa, es decir, que trabaja o está en búsqueda de trabajo.
} 
encima de la tasa global de participación total y 15,4\% con respecto a la participación laboral de las mujeres.

Sin embargo el incremento de la mujer en el mercado laboral ha traído consigo una desigualdad en los ingresos laborales, tanto así que para 1976 y 1995 el diferencial salarial cambio del 36\% al 21\% (Ribero \& Meza, 1997). Este hecho ha incentivado a realizar diversos trabajos que analicen el efecto de la creciente participación de la mujer en el mercado laboral, ya que con el paso del tiempo las mujeres han cambiado su rol en la sociedad como ama de casa, lo cual conlleva un incremento en sus aportes en el hogar ${ }^{2}$. Un ejemplo de las diversas investigaciones generadas por este fenómeno son los trabajos que estudian el diferencial salarial por género, los cuales han sido explicados por diferencias en roles de género, estructura salarial o discriminación laboral. No obstante, existen más componentes que explican las diferencias salariales, ejemplo de ello, los diferentes mercados geográficos, salarios de eficiencia y compensatorios. Así mismo, la discriminación laboral se puede dar por diferencias en las probabilidades de acceso y posterior ascenso en el trabajo remunerado, siendo difícil de observar y medir, puesto que no existen estadísticas que determine estas restricciones.

Por su parte, la discriminación salarial en los últimos años se ha convertido en una buena alternativa para analizar esta problemática, utilizando la técnica de Oaxaca (1973) y Blinder (1973), la cual permite descomponer el diferencial salarial promedio entre hombres y mujeres en dos componentes: el primero que explica la brecha salarial por las diferencias en sus características productivas (educación, edad, experiencia laboral, entre otras) y un segundo componente que está explicado por diferencias y combinaciones de características o factores no observables, que no solo interfiere en la productividad de los individuos, también afecta la remuneración salarial dada sus características productivas ${ }^{3}$. Esto genera una especie de discriminación hacia cierto grupo en este caso las mujeres. A pesar de ser una técnica sencilla, tiene la limitación de solo analizar los determinantes de la brecha en el

\footnotetext{
${ }^{2}$ Entiéndase como aportes al hogar a todas las actividades diarias no remuneradas que la mujer desempeña para mantener su familia u hogar.

${ }^{3}$ Los hombres pueden tener un mayor salario por hora con respecto a las mujeres así tengan iguales características productivas.
} 
promedio de los salarios, en otras palabras, no se estudia que sucede con el diferencial en toda la distribución del ingreso laboral.

Es por ello, que este trabajo busca contribuir al estudio del diferencial salarial en Colombia, analizando la evolución en los últimos años de la brecha salarial en los ingresos promedios y también en toda la distribución de salarios. Para ello se cuenta con información durante el periodo 2004 - 2012, tiempo en el cual se crea la Ley 1496 de 2011 con el objetivo de garantizar la igualdad salarial por género, fijando los mecanismos necesarios para que dicha igualdad sea real. Para poder analizar el comportamiento del diferencial salarial se utilizan las encuestas empalmadas MESEP - DANE para los años 2004, 2008 y 2012 junto con la metodología propuesta por Melly (2005), la cual propone realizar descomposiciones de la brecha salarial en diferentes puntos de la distribución incondicional de los salarios.

El resto del documento se organiza de la siguiente manera: En la sección 2 se realiza una revisión de la literatura teórica y empírica, como también antecedentes en América Latina y Colombia; la sección 3 presenta los datos con las variables utilizadas y las estadísticas descriptivas; la sección 4 describe la metodología utilizada para la estimación y descomposición del diferencial salarial; en la sección 5 muestra y analiza los resultados obtenidos y por último en la sección 6 se concluye.

\section{Revisión de la literatura}

Toda diferencia de salarios no constituye discriminación, ni toda discriminación laboral explica las diferencias salariales (Bernat, Ribero \& Tenjo, 2005). Dado que existen diversos factores como las características del individuo que reflejan productividad, diferentes salarios compensatorios por trabajos peligrosos o desagradables y efectos de salarios relativos en diferentes regiones y actividades económicas, lo cual puede generar brechas salariales que no puede ser dada por la discriminación laboral de género. Solo puede existir discriminación salarial cuando dos individuos con igual características productivas (educación, edad, experiencia, laboral, etc) y habilidades realizan el mismo trabajo pero uno remunera más ingreso que el otro. De igual manera se puede establecer otras 
discriminaciones laborales en cuanto a la probabilidad de acceder a un trabajo ${ }^{4}$, el tratamiento diferente en los beneficios laborales y las oportunidades de acenso.

Existen varios trabajos que analizan los determinantes del diferencial salarial por género, los cuales han sido discutidos en la literatura sobre discriminación laboral, un ejemplo de ello es el trabajo desarrollado por Weichselbaunner \& Ebner (2005). Esta investigación ofrece un análisis cuantitativo de la literatura empírica sobre la discriminación laboral por género desarrolladas hasta el año 2005, controlando por metodologías, datos, países y periodos de tiempo de las publicaciones. Para ello utilizan la literatura económica indexada con referencias: salario, género y discriminación salarial o laboral. Los autores encuentran (usando los factores necesarios para clasificar los estudios que cumplan esta temática) que países como Estados Unidos con 614, Reino Unido con 87, Taiwán con 77, Australia con 63 y Canadá con 60 son los países que mayores publicaciones tienen sobre este fenómeno. Para América Latina los países con mayores publicaciones son México y Perú con 22, Brasil con 19, Chile con 14, Argentina y Uruguay con un total de 7. Por su parte, Colombia aparece con tan solo 6 trabajos referentes al tema del diferencial salarial por género ${ }^{5}$.

\subsection{Evidencia teórica}

La literatura internacional plantea ciertos enfoques que pueden explicar bajo algunos supuestos los diferenciales salariales por género. Uno de los más importantes es la teoría económica de la discriminación ${ }^{6}$, dividiéndose en la teoría de discriminación por "gustos o preferencias" desarrollada por Becker (1971) y la teoría de discriminación "estadística" realizada por Arrow (1971) y Phelps (1972).

La teoría de la discriminación por "gusto o preferencias" desarrollada por Becker se basa en el prejuicio de los agentes en el mercado laboral (empleador, empleado y consumidor). La idea consiste en que los agentes incurren en costos o están dispuestos a pagar para evitar ciertos grupos (minorías). Según Becker la discriminación está representada por un

\footnotetext{
${ }^{4}$ Lo cual establece que dos individuos a pesar que tengan iguales características productivas, uno de ellos tiene mayor probabilidad te acceder a un empleo.

${ }^{5}$ Cabe destacar que la investigación incluye solo los trabajos publicados en inglés.

${ }^{6}$ Este enfoque hace parte del modelo de discriminación competitivo, en el cual los individuos solo buscan maximizar sus beneficios.
} 
coeficiente $\delta$ también conocido como coeficiente de desagrado, este coeficiente se relaciona con las características del trabajador que observa el empleador y no con la productividad de los empleados. Entonces un empleador es discriminador si paga un salario $w$ al grupo discriminado (B) y $w+\delta$ al grupo no discriminado (A), a pesar que ambos grupos tenga las mismas características productivas.

Como consecuencia de esta situación se genera una disminución en el bienestar para el grupo discriminado y en la empresa, ya que al discriminar se debe incurrir a mayores costos. No obstante, bajo competencia prefecta este tipo de discriminación tiende a ser insostenible, debido a que las empresas que no discriminan pagan un salario menor al grupo discriminado, trayendo consigo un incremento en el ingreso y finalmente terminarían por sacar a las empresas discriminadoras del mercado. Así mismo, otros tipos de competencia como los monopolios o monopsonios discriminadores pueden mantenerse en el tiempo, dada su característica de poder establecer el precio.

Por su parte, la teoría de discriminación "estadística" surge cuando un empleador infiere características productivas al trabajador a partir de rasgos observables (raza y género). Esto se debe a que las empresas tienen información limitada de las habilidades de los individuos, siendo costosa de adquirir; es por ello que el empleador basa sus decisiones en las características observables que no afectan directamente la productividad pero que pueden estar correlacionadas con características no observables que la afectan. Sin embargo con el paso del tiempo el empleador puede constatar la productividad del individuo, lo que conlleva a que la brecha salarial no se explique principalmente por las características observables que utilizó el empleador para inferir productividad.

La discriminación estadística surge por inferir productividad de un individuo en base a la pertenencia de este en cierto grupo, y no tener en cuenta sus características y habilidades individuales, por ejemplo en un trabajo que se requiera cierta fuerza física una mujer que aspira al trabajo puede no ser seleccionada por el empleador (el cual infiere su productividad evitando incurrir en costos elevados), debido a la creencia que las mujeres tienen menor fuerza física con respeto a los hombres, independientemente de la fuerza física que tenga la aspirante. En general Arrow (1972) plantea que se debe tener tres 
elementos a tener cuenta en la existencia de discriminación estadística: 1) el empleador tiene la capacidad de inferir a qué grupo pertenece cada individuo, 2) existe información limitada de la productividad individual y el empleador debe incurrir en costo para conocerla y 3) el empleador tiene algún conocimiento o puede distinguir productividad para los distintos grupos de individuos.

Siguiendo la descripción de los enfoques que explican las brechas salariales por género, se considera otra alternativa que analice las diferencias en ingresos laborales entre hombres y mujeres, esta se conoce como roles de género. Este enfoque tiene como fundamento el costo de oportunidad de las mujeres de trabajar o dedicarse a las actividades del hogar ${ }^{7}$. Las mujeres por su rol que desempeñan en el hogar deciden o no salir al mercado laboral, es por ello que solo trabajan las mujeres cuyo salario sea mayor que su salario de reserva, el cual es más alto que los hombres debido a la elevada productividad que deben tener como trabajadoras en labores de madre y ama de casa. Esta condición puede generar un posible sesgo de selección a la hora de estimar los ingresos laborales de las mujeres, ya que las mujeres que participarían en el mercado laboral serían aquellas con mayor probabilidad de tener mayores salarios.

Existen diversos trabajos empíricos que analizan esta problemática, uno de ellos es el realizado por Alesina, Giuliano \& Nunn (2011), el cual busca establecer los orígenes históricos de las diferencias actuales del papel de la mujer en la sociedad. Los autores ponen a prueba la hipótesis que las prácticas agrícolas tradicionales influyeron en la división sexual del trabajo, su historia y la evolución de los roles de género. Ellos encuentran que los descendientes de civilizaciones que practicaban la agricultura del arado tienen menores tasas de participación en política y actividades empresariales para el género femenino; debido a que este tipo de práctica agrícola requiere mayor fuerza física (en estas sociedades los hombres tienden a especializarse en actividades agrícolas y las mujeres en trabajos domésticos del hogar). Por su parte, en las sociedades surgidas bajo la agricultura de rotación de cultivos las mujeres tenían mayor participación en las actividades de cultivo,

\footnotetext{
${ }^{7}$ El incremento de las mujeres en el mercado laboral ha estado acompañado con la idea que las mujeres son las responsables del hogar y la familia. Esta situación crea una segregación en el mercado laboral y por ende una brecha salarial, como respuesta a la disponibilidad de tiempo de las mujeres en el trabajo.
} 
esto trajo consigo mayor igualdad de los roles de género en la sociedad que utilizó este de tipo de prácticas agrícolas.

Por otro lado, el trabajo empírico desarrollado por Anderson, Blinder \& Krause (2003) busca explicar el diferencial salarial de las madres con y sin hijos. Utilizando la Encuesta Nacional Longitudinal de Mujeres Jóvenes para el periodo de 1968-1988, muestran que las características del capital humano y las variables no observables explican el 55\% y 57\% de la brecha salarial. Más detalladamente sugieren que las madres con hijos tienden a tener un salario más bajo con respeto a las madres sin hijos, debido a que las madres con hijos deben reducir su esfuerzo en el trabajo como consecuencia del tiempo que deben dedicar al cuidado de sus niños.

Los trabajos explicados anteriormente tienen a la heterogeneidad no observada como una de las posibles causas que explican el diferencial salarial por rol de género. Trabajo como el de Becker (1985), el cual establece la existencia de alguna heterogeneidad no observada por parte del empleador para las mujeres casadas y solteras, hace muy difícil inferir la productividad entre ellas. Esta teoría se basa en que las mujeres con hijos presentan mayor ausentismo y distracción en el trabajo, dado que las mujeres tienen actividades por fuera de la jornada de trabajo como lo es el cuidado de la familia. Según el empleador esta situación trae consigo una especie de disminución del capital humano por parte del trabajador (se valora cada vez más su presencia en las actividades laborales), trayendo consigo diferentes remuneraciones y penalidades para el género femenino.

Según Fernández (2006), un enfoque adicional que puede explicar el diferencial salarial entre hombres y mujeres es a través de la estructura salarial, realizado por Blau (1996). Este enfoque plantea que el diferencial salarial por género está dado por los desiguales precios de las habilidades de los individuos en el mercado de trabajo y los ingresos recibidos por empleos que se consideran poco deseables para la sociedad. El primer efecto puede darse por las diferentes formas de valorar las características productivas de los individuos. Ejemplo de ello, en un trabajo que necesite fuerza física se valorará más en los hombres. El segundo efecto consiste en el aumento del ingreso por actividades laborales no deseables para los individuos como lo son: trabajos con poca flexibilidad laboral, gran 
estrés, mayores riesgos físicos o psicológicos en los cuales tanto hombres y mujeres pueden ser adversos.

\subsection{Evidencia empírica}

Como se puede observar el fenómeno del diferencial salarial por género ha sido tratado de manera exhaustiva por la teoría económica. No obstante, la literatura empírica internacional y nacional han tenido una serie de dificultades en tratar de contrastar que factores inciden en el diferencial salarial entre hombres y mujeres, dando mayor peso a los roles de género que a los factores de tipo discriminatorio. Sin embargo esto no quiere decir que no se haya desarrollado estudios empíricos que analicen el diferencial salarial por género utilizando la teoría de la discriminación; por el contrario las dificultades en la estimación y obtención de información adecuada han sido una de las causas que restringen y a su vez incentiven el estudio de esta problemática.

Uno de los trabajos empíricos más importantes es el realizado por Goldin \& Rouse (1999), ellos buscan establecer la probabilidad de ingreso de la mujer en las orquestas filarmónicas en Estados Unidos para el periodo de 1970-1995. Utilizando un cuasi experimento el cual cambia la metodología de ingreso en un esquema de audiciones a ciegas. Los autores encuentran que bajo este esquema las mujeres tienen un 50\% más de probabilidad de avanzar a otra ronda en la audición, incrementando a su vez la probabilidad de que sea seleccionada finalmente.

No obstante, los trabajos desarrollados hasta el momento presentaban el problema de sesgo de selección, el cual puede surgir por dos razones: primer lugar, este se puede generar por decisiones en el diseño muestral, es decir, por la decisión que tome el investigador en el diseño de la muestra, ejemplo de ello, cuando se utiliza un cierto tipo de muestreo. La segunda razón surge cuando las decisiones económicas de los individuos son autoseleccionadas, en otras palabras, los individuos puede autoseleccionarse ellos mismos para pertenecer a un cierto grupo. Esto ocurre cuando los individuos deciden participar o no en el mercado laboral, dependiendo si el salario que recibe en el mercado es superior a su salario de reserva, esto con lleva a inferir que la decisión de participar en el mercado laboral es endógena al modelo. Para la mujer participar o no en el mercado laboral va a 
depender de los roles que desempeñe en el hogar como madre y esposa. Dado este problema de sesgo de selección, Buchinsky (1998) aplica una técnica de regresión por cuantiles que le permite analizar las características de la oferta de trabajo de las mujeres en Estados Unidos, teniendo en cuenta el problema de sesgo de selección. Para ello utiliza un método semiparamétrico en dos etapas similar al utilizado por Heckman (1979) en los modelos de regresión.

En Latinoamérica existen muchos trabajos que tratan esta problemática, sin embargo se destaca por completo la investigación desarrollada por Bernat, Ribero \& Tenjo (2005), el cual analiza la situación de la mujer en el mercado laboral para seis países de América Latina (Argentina, Brasil, Colombia, Costa Rica, Honduras y Uruguay) durante las dos últimas décadas del siglo XX. Ellos encontraron que tanto hombres y mujeres en edades intermedias tienen mayor participación en el mercado laboral, sin embargo para el género femenino esta participación ha estado acompañada con un aumento en su tasa de desempleo ${ }^{8}$.

Con respecto al diferencial salarial por género, los autores encuentran que existe una disminución significativa ${ }^{9}$, esto debido principalmente a la preferencia de los hombres por trabajar más horas a la semana. Así mismo, la segmentación laboral contribuye al diferencial salarial por género, ya que si bien las mujeres se concentran en las actividades laborales con mayor salario, sus remuneraciones son menores al interior de los sectores y ocupaciones.

En Colombia se han realizado diversos trabajos que estudien el diferencial salarial por género, sin embargo la mayoría de trabajos se han concentrado en analizar este fenómeno a través de la discriminación salarial, siguiendo el procedimiento de estimar ecuaciones de salario $^{10}$ y descomponiendo el diferencial salarial utilizando la metodología de OaxacaBilnder (1973). Uno de los primeros trabajos fue el realizado por Tenjo (1993), el cual estudia la brecha salarial por género en Colombia durante el periodo de 1976-1985. Con

\footnotetext{
${ }^{8}$ Brasil con una tasa de desempleo femenino del $18 \%$, es el país con la menor incapacidad de inserción de la mujer en el mercado laboral.

${ }^{9}$ Especialmente en los países de Argentina, Colombia y Honduras.

${ }^{10}$ También conocidas como ecuaciones de Mincer.
} 
ayuda de la Encuesta Nacional de Hogares (ENH), Tenjo encuentra que si bien existe una brecha salarial entre hombres y mujeres, esta no solo es explicada por las diferencias en las características observables (educación, edad, etc), también es explicado por el término de discriminación (efecto remuneración), el cual tuvo un comportamiento creciente.

Baquero (2001) analiza el diferencial salarial por género en Colombia para el periodo 19841999, siendo de la misma línea al estudio de Tenjo (1993). Utilizando de igual manera la Encuesta Nacional de Hogares (ENH) y teniendo en cuenta para la estimación los trabajadores privados, del gobierno y domésticos. El autor encuentra que si bien durante el periodo de estudio hubo un incremento en la educación de los individuos, esta fue mayor para las mujeres; sin embargo, los retornos para la educación fueron disminuyendo con relación a las mujeres, esto es debido a su aumento de participación laboral. Así mismo, el componente de discriminación tuvo una tendencia creciente, lo cual llego a contribuir en un $29 \%$ en el diferencial salarial para los primeros años, siendo decreciente hasta a los finales del 90 donde la crisis económica incremento la brecha salarial, llegando al 34\%.

Por otra parte, Abadía (2005) estudia la discriminación estadística por sexo en el mercado laboral colombiano para tres grupos de individuos: hijos del jefe del hogar de 30 o menos años, de 20 años o más casados o en uniones libres y solteros de 20 años o más. La idea que maneja Abadía, es que existe discriminación estadística por parte de las firmas si con el paso de los años el salario del individuo está cada vez menos relacionado con sus características observables como lo es la edad y la educación ${ }^{11}$. Los resultados muestran que en el sector público no existe evidencia de discriminación estadística. Todo lo contrario sucede para el sector privado, el cual presenta algún resultado para individuos casados o en unión libre.

Por otro lado, un estudio importante fue el desarrollado por Fernández (2006), el cual analiza los determinantes del diferencial por género en Colombia para el periodo 19972003, utilizando la Encuesta de Calidad de Vida (ECV). Este trabajo resalta sobre los analizados anteriormente en Colombia, por ser el primero en utilizar la metodología de

\footnotetext{
${ }^{11}$ Siendo una parte del efecto discriminación que se obtiene utilizando las diferentes metodologías de descomposición salarial.
} 
regresión por cuantiles (quantile regression) y la descomposición del diferencial salarial realizada por Machado y Mata (2005), estudiando los determinantes de la brecha salarial en los diferentes puntos de la distribución de salarios. Los resultados obtenidos muestran que existen diferencias salariales entre hombres y mujeres en los valores extremos en la distribución de salarios, como es el caso del percentil 95, en el cual las mujeres ganan un $11,5 \%$ menos con respecto a los hombres para el año 2003. La autora establece que este diferencial no se explica por diferencias en las características productivas entre hombres y mujeres, se da por la remuneración salarial diferente que percibe por género.

Bernat (2007) calcula las curvas de discriminación de las mujeres asalariadas en Colombia para los años 2000, 2003 y 2006, utilizando la Encuesta Continua de Hogares (ECH). Estas curvas permiten estudiar la discriminación salarial en toda la distribución del ingreso laboral y no solo el promedio de los salarios. Dado esto la autora analiza tres aspectos en el diferencial salarial por género no estudiado en ese momento en Colombia. Número de mujeres discriminadas (incidencia), el grado de discriminación (intensidad) y que tan desigualmente están tratadas las mujeres bajo un cierto grupo. Los resultados obtenidos muestran que para el año 2000 existe poca intensidad en la discriminación con respecto al año 2006, en donde la curva de discriminación es mayor. En cuanto al número de mujeres discriminadas esta fue mayor en el año 2006, lo cual refleja el alto grado de desigualdad que existe al interior de la información para cada periodo de estudio. Así mismo, Bernat encuentra una especie de "Techo de Cristal", ya que son las mujeres más educadas las que presentan mayor diferencial salarial con relación a los hombres.

Más adelante se encuentra el trabajo de Tenjo \& Herrera (2009), el cual estudia la discriminación salarial por género y origen étnico. Ambos autores recurren a la Encuesta de Calidad de Vida (ECV) para el año 2005, utilizando la metodología Oaxaca - Blinder (1973). Ellos encuentran que las brechas salariales no están explicadas por diferencias en el capital humano entre hombres y mujeres, ya que al analizar los datos se obtiene que las mujeres tienen una concentración relativamente mayor en las ocupaciones con respecto a los hombres. Adicionalmente a ello, son las mujeres las que poseen mayor cualificación (años educación, experiencia laboral, etc), sin embargo al descomponer la brecha salarial se 
encuentra que dicha diferencia está explicada solamente por el efecto discriminación, puesto que las diferencias en el capital humano son negativas, favoreciendo a las mujeres.

Para finalizar existe el trabajo realizado por Galvis (2010) utilizando la Gran Encuesta de Hogares durante el año 2009 estima el diferencial salarial por género en los diferentes puntos de la distribución del ingreso laboral en las trece principales ciudades de Colombia. Los resultados obtenidos sugieren que las brechas salariales no son explicadas por las características observables del individuo, tales brechas son explicadas en su mayoría por la remuneración de los atributos productivos, lo cual implica la posible existencia de discriminación salarial por género. El estudio por ciudades arroja que las ciudades con mayor concentración de la actividad económica (Bogotá, Medellín, Cali, Manizales y Pereira) tienen menor brecha bruta con respecto a las ciudades periféricas, las cuales tienen mayor discriminación salarial. El autor también encuentra en el promedio nacional y en las diferentes ciudades, el salario mínimo presenta un punto de quiebre a partir en el cual las brechas salariales por genero tienden a disminuir.

Como se pudo observar los diferentes estudios del diferencial salarial por género se concentran en analizar las diferencias en la media de la distribución de los ingresos laborales. No obstante, existen pocos trabajos que estudien la brecha salarial por género en los diferentes puntos de la distribución del ingreso, es decir, analizar el fenómeno conocido en la literatura como "Techos de Cristal” y más aún importante aún es difícil encontrar estudios que analicen la evolución de este fenómeno en los últimos años en Colombia.

\section{Datos y estadísticas descriptivas}

Para analizar el diferencial salarial por género en Colombia durante los años 2004, 2008 y 2012 se utilizan las encuestas empalmadas del programa MESEP - DANE ${ }^{12}$, debido a que se especializa en estudiar el mercado laboral e identificar las diferentes variables socio demográficas que inciden en la vida de los individuos. Así mismo, la MESEP se caracteriza por ser una metodología de empalme entre la Encuesta Continua de Hogares y La Gran

\footnotetext{
${ }^{12}$ Misión para el Empalme de las Series de Empleo, Pobreza y Desigualdad del Departamento Administrativo Nacional de Estadística.
} 
Encuesta Integrada de Hogares ${ }^{13}$, debido a que el periodo estudiado está sujeto a cambios metodológicos en las encuestas de hogares ${ }^{14}$.

Como se analizó anteriormente en la literatura, el incremento de la participación de las mujeres en el mercado laboral ha estado acompañando de un aumento en los trabajos de tiempo parcial debido al rol de género de las mujeres, lo cual las obliga a dedicar tiempo en las actividades del hogar. Este resultado ha generado que los trabajos de tiempo completo se concentren mayormente en los hombres, permitiendo un desempleo involuntario y una discrepancia en los salarios entre hombres y mujeres. Por ello, en este trabajo se utiliza como grupo de estimación los trabajadores con edad entre 18 y 65 años con ingreso laborales positivos en su trabajo principal y que trabajen semanalmente. En la mayoría de trabajos utilizan el ingreso laboral horario como variable de análisis; para este trabajo se construyó la variable de salario por hora teniendo en cuenta los lineamientos en la homogenización de los datos y la construcción de variables de ingreso.

Por otra parte, los trabajadores del servicios doméstico como los jornaleros se tomaron en las estimaciones como un solo tipo de trabajo, dado que son trabajos que se caracterizan por tener poca cualificación y baja remuneración, el primero está representado mayormente por mujeres, debido a sus características laborales, lo contrario sucede con los jornaleros donde la mayoría son hombres. Así mismo, con el objetivo de capturar los efectos de las diferencias salariales generada por los roles de género y la estructura salarial, se incluyen variables como: individuos casados, jefes del hogar y trabajadores del gobierno.

Teniendo en cuenta lo anterior, las tablas la y $1 \mathrm{~b}$ muestran el salario promedio por género y nivel educativo durante el periodo 2004 - 2012. Como se puede observar, la brecha promedio en el ingreso laboral horario se ha disminuido a favor de las mujeres con el paso del tiempo, pasando del 23,3\% en el año 2004 a 17,7\% durante el 2012. Al estimar los cuantiles 10, 50 y 90 del salario por hora entre hombres y mujeres, se encuentra una reducción del diferencial salarial, a excepción del 10\% de los individuos con menor ingreso, el cual paso de tener una brecha de $12,6 \%$ en 2004 a 15,1\% para el año 2012. Una

\footnotetext{
${ }^{13}$ La Encuesta Continua de Hogares se desarrolló para el periodo 2000 - 2005, por su parte la Gran Encuesta Integrada de Hogares empieza a partir del año 2008.

${ }^{14}$ La metodología corrige la construcción de variables como ingreso, además corrige la omisión de variables, valores extremos, entre otros.
} 
vez estimados los cuantiles del salario, se obtuvieron los rangos intercuantílicos 90-10, 9050 y $50-10$, se observa que la desigualdad salarial por género se ha reducido, principalmente los individuos con menores salarios (rango intercuantílico 50-10) pasando de $14,8 \%$ en 2004, 7\% en 2008 y -3\% para 2012.

Con respecto al salario promedio por género y nivel educativo, se obtuvo que los hombres en promedio remuneran más ingreso laboral por hora con relación a las mujeres en todo nivel educativo, siendo media y superior los niveles con mayor brecha en el ingreso laboral. Así mismo, se puede observar que la brecha en el salario horario se incrementa con el paso de los años, pasando en 2004 de 3,7\%, 28,8\% y 21,7\% para básica primaria, media y superior respectivamente, a registrar una brecha en 2012 de 8,4\%, 35,7\% y 30,7\%.

En cuanto a la desigualdad salarial por género en cada nivel educativo, las estimaciones muestran que el nivel de educación primaria es el único que presenta una disminución en la desigualdad salarial para todos los rangos intercuantílicos. Por el contrario los niveles de educación media y superior presentan una disminución en su diferencial salarial en los individuos con menores ingresos (rango intercuantílico 50-10); los demás rangos muestran un incremento en la desigualdad salarial, siendo los individuos de mayores salarios (rango intercuantílico 90-50) y educación superior los de mayor crecimiento, pasando de $14,2 \%$ en 2004 a $58,3 \%$ para 2012.

Las tablas 3 a y 3 b presentan ciertas estadísticas descriptivas de los individuos por género, con relación a sus características personales, tipos de trabajo y características regionales. Como se puede observar, las mujeres son más educadas en promedio que los hombres, generando una brecha educativa que se incrementa a través del tiempo ${ }^{15}$; así mismo las mujeres de la muestra son aproximadamente más jóvenes que los hombres, a excepción del año 2012; sin embargo, en los hogares son los hombres los que tienen más hijos menores de 18 años.

\footnotetext{
${ }^{15}$ Es posible que exista diferencia en calidad educativa, dado que las instituciones educativas privadas suelen tener mejores estándares de calidad que las instituciones públicas, sin embargo solo los grupos de población con mayores ingresos pueden acceder a la formación educativa privada.
} 
Con respecto a los tipos de trabajo existen diferencias entre ambos grupos: se tiene mayor proporción de trabajadores hombres en el sector privado, con una diferencia promedio del $2 \%$ durante el periodo de estudio. De igual manera sucede en la actividad cuenta propia, con mayor proporción para los hombres (una diferencia promedio de $2 \%$ ); sin embargo son las mujeres cuentapropistas las que registran un mayor crecimiento a través del tiempo, generando una reducción en esta brecha, la cual para el año 2012 es de apenas el 1\%. Para la actividad laboral de directores o patrones lo resultados son similares, los hombres tienen mayor participación; no obstante a diferencia de los cuenta propia su brecha con respecto de las mujeres se mantiene constante con el paso de los años (aproximadamente 3\%).

Por el contrario en la proporción de empleados del gobierno y domésticos ${ }^{16}$ se encuentra una diferencia a favor de las mujeres, siendo ambas decrecientes durante el periodo de estudio, pasando de 3\% y $8 \%$ en 2004 a $1 \%$ y $3 \%$ para el año 2012. Para el caso de la proporción de asalariados ${ }^{17}$ por género, las estimaciones muestran un cambio en favor de los hombres, para el año 2012 el 57\% de los hombres son salariados, un punto porcentual por encima del promedio de mujeres asalariadas para el mismo año.

Analizando las características regionales, se encuentra una concentración de la población en la región central con una tendencia creciente con el paso del tiempo, 58\% mujeres y $54 \%$ hombres para el año 2012. El resto de la población se concentra en las demás regiones (Atlántica, Pacifica y Orinoquia) y como se puede observar estas han presentado una disminución en su población, es decir, existe un tipo de desplazamiento de población hacia la región central. Galvis (2011) menciona que la población en Colombia se concentra en aquellas ciudades donde se tiene mayor desarrollo de las actividades económicas, más oportunidades de empleo y educación, contrario a lo que sucede en las ciudades periféricas.

Para finalizar la gráfica 3 presenta funciones de densidad del logaritmo natural del salario horario en hombres y mujeres para los años 2004, 2008 y 2012. La densidad en el salario de los hombres tiene una diferencia positiva con respecto a la densidad del salario de las mujeres para los individuos con menores ingresos, lo cual indica una diferencia en el

\footnotetext{
${ }^{16}$ Lo componen los trabajadores en el servicio doméstico como jornaleros.

${ }^{17}$ Incluye todas las actividades laborales a excepción de cuenta propia.
} 
promedio del salario horario entre género. No obstante, a medida que se incrementa el salario horario la diferencia en la densidad del salario horario entre hombres y mujeres disminuye, esto sucede en cada año de estudio.

\section{Metodología}

Según las estadísticas obtenidas anteriormente existe una diferencia en el ingreso laboral horario promedio entre hombres y mujeres, sin embargo el análisis de la brecha salarial por género con lleva a ir más allá de un análisis descriptivo. Como se explicó en la revisión de la literatura, empíricamente el diferencial salarial entre hombres y mujeres puede deberse a diversos componentes del mercado laboral. Primero, puede haber diferencias en el capital humano entre hombres y mujeres, lo cual conlleve a que cierto grupo tenga mejores características productivas y por ende mayor ingreso laboral ${ }^{18}$. En segundo lugar, la calidad de la educación puede generar mayor productividad en ciertos grupos de individuos ${ }^{19}$, trayendo consigo una diferencia en los salarios. Otra diferencia que puede explicar la brecha salarial es la segregación ocupacional y regional para cierto grupo de individuos, lo cual hace que existan grupos que se concentren en actividades mejor remuneradas. Así mismo, la posibilidad de que exista heterogeneidad en la distribución de los asensos hacia cierto grupo de individuos (para este caso el género) hace que exista una brecha en los salarios. En otras palabras existen diversos factores que explican la brecha salarial entre grupos, ya sean años de educación, calidad educativa, experiencia laboral, actividad económica, región y demás.

De todo esto la literatura empírica se ha encargado principalmente de estudiar el diferencial salarial respondiendo esta pregunta: ¿qué sucede con la brecha salarial entre hombres y mujeres si no hubiera diferencias en sus características productivas observables? La metodología de Oaxaca - Blinder trata de responder este interrogante, descomponiendo el diferencial salarial en dos componentes: el primero ya conocido como efecto dotación o

\footnotetext{
${ }^{18}$ Por ejemplo la tabla 2 muestra que durante el periodo de estudio las mujeres tienen menor ingreso laboral horario promedio que los hombres, no obstante al analizar ciertas características observables se encuentra que es el género femenino posee mayores años de educación.

${ }^{19}$ Debido a que el grupo con mejor calidad educativa, puede obtener más conocimiento y por ende mejores habilidades productivas.
} 
características, el cual explica la brecha a través de las diferencias en las características y el segundo efecto remuneración o discriminación que queda luego de controlar estas características productivas y que a su vez comprende demasiados factores, entre los cuales se encuentra las diferencias en habilidades innatas de los individuos (inobservables), preferencias de los individuos, capacitaciones en el trabajo, como también diferencias en la remuneración de sus características productiva y discriminación salarial.

No obstante, como se mencionó anteriormente la discriminación salarial es una parte del componente no explicado por sus características productivas, lo cual con lleva asociar que el efecto remuneración no está explicado solamente por la discriminación salarial, sin embargo estimar estos factores es difícil, debido a la disponibilidad de información que se tiene, es decir, se tiene un problema de omisión de variables, esto tiende a sobrestimar el grado de discriminación, ya que no se incluye en el efecto remuneración aquellas diferencias que vienen dadas por características omitidas. Igualmente es difícil diferenciar algunos efectos como lo puede ser la desigualdad de acceso u oportunidades y las preferencias antes que los individuos ingresen al mercado laboral, ejemplo de ello, la calidad educativa de las instituciones públicas y privadas, en donde las últimas solo pueden ser accesibles para individuos con elevados ingresos. Este es tan solo un ejemplo de la dificultad de diferenciar los efectos no observados, sin embargo en esta investigación no se abarcará este problema, ya que solo interesa el diferencial salarial para individuos que ya ingresaron en el mercado laboral.

Para descomponer la brecha salarial entre hombres y mujeres se debe primero estimar las siguientes funciones de salarios:

$$
\ln \left(w_{j}\right)=X_{j} \beta_{j}+v_{j} \quad ; \quad j=h, m
$$

Donde $j=h, m$ indica el grupo que pertenece a los hombres $(h)$ o las mujeres $(m), \ln \left(w_{j}\right)$ es el logaritmo del salario horario, $X_{j}$ es la matriz de características observables que intervienen en la productividad, $\beta_{j}$ es un vector de coeficientes que presenta los retornos que se obtiene en el mercado de las características observables en $X_{j}$ para cada grupo $j$. 
Para finalizar $v_{j}$ es un término no observable que se distribuye normalmente con media condicional cero $\left[E\left(v_{j} \mid X\right)=0\right]$ y varianza $\sigma^{2}$. Entonces al descomponer el logaritmo del salario horario entre hombres y mujeres se obtiene.

$$
\ln \left(w_{h}\right)-\ln \left(w_{m}\right)=\left(X_{h} \beta_{h}-X_{m} \beta_{m}\right)-\left(v_{h}-v_{m}\right)
$$

Puesto que el género es una variable binaria que puede tomar el valor de uno si es hombre $\left(D_{h}=1\right)$ y cero si es mujer $\left(D_{h}=0\right)$ y dado que la regresión cumple con la propiedad de estimar en sus medias muestrales, la brecha bruta del salario horario puede expresarse:

$$
\Delta_{w}=E\left(\mathrm{w}_{h} \mid D_{h}=1\right)-E\left(\mathrm{w}_{m} \mid D_{h}=0\right)
$$

Entonces la ecuación de salarios para hombres y mujeres se estima en sus medias muestrales.

$$
\bar{w}_{h}^{\prime}=\bar{X}_{h} \hat{\beta}_{h} \quad ; \quad \bar{w}_{m}^{\prime}=\bar{X}_{m} \hat{\beta}_{m}
$$

Donde $\bar{w}_{j}^{\prime}$, es el promedio del salario horario para hombres y mujeres, $\bar{X}_{j}$ es la media de las características observables y $\hat{\beta}_{j}$ son los coeficientes estimados. Ahora construyendo un término contrafactual, el cual muestre el salario que tendría las mujeres si fueran remuneradas como los hombres $\bar{X}_{m} \hat{\beta}_{h}$, utilizando las ecuaciones (3) y (4), sumando y restando el contrafactual se obtiene:

$$
\hat{\Delta}_{w}=\underbrace{\left(\bar{X}_{h}-\bar{X}_{m}\right) \hat{\beta}_{h}}_{\text {Efecto caraterisicicas }}+\underbrace{\bar{X}_{m}\left(\hat{\beta}_{h}-\hat{\beta}_{m}\right)}_{\text {Efecto remuneración }}
$$

El primer componente es la diferencia en el salario promedio de los hombres y el término contrafactual de las mujeres si son remuneradas como los hombres, en otras palabras parte que explica la brecha salarial por las diferencias en las características productivas entre hombres y mujeres, conocido como efecto característica. Por su parte, el segundo componente es la diferencia en el ingreso promedio contrafáctico y el salario promedio 
observado de las mujeres, ya que solo interesa la diferencia de la remuneración en las características observables ${ }^{20}$. Este componente se conoce como efecto remuneración y evalúa la posible discriminación salarial. Cabe aclarar que este método presenta el problema de sesgo de estimación, debido a que las funciones de salarios pueden explicarse por factores no observables como lo son las habilidades innatas, preferencias, calidad educativa, entre otros (variables omitidas). Es por ello que la discriminación salarial es una parte de este componente, siendo un componente sobrestimado.

No obstante, debido a su rol de madre las mujeres acceden al mercado siempre y cuando su salario sea mayor al salario del mercado, el cual les permita cubrir el costo de oportunidad en el desempeño de labores de madre y ama de casa, generando un sesgo de selección. Para corregir este sesgo se aplica la metodología de Heckman (1979) a través de dos etapas. La primera etapa estima la probabilidad que el salario de los individuos se explique utilizando como instrumento la tenencia de hijos en el hogar menor de 18 años junto al resto de características observables.

$$
\operatorname{Pr}\left(w_{h, m} \mid X_{h, m}\right)=\theta\left(X_{h, m}^{\prime} \delta\right)
$$

Una vez calculado en la primera etapa la probabilidad del salario junto a las características que influyen en el rol de madre se estima paramétricamente la inversa del de $\operatorname{Mills}^{21}\left(\lambda_{h, m}\right)$, la cual se introduce en la segunda etapa como una variable explicativa adicional que corrige el sesgo de selección. Dado esto el diferencial salarial horario promedio por género se representa a partir de la siguiente ecuación:

$$
\ln \left(w_{h}\right)-\ln \left(w_{m}\right)=\left(X_{h} \beta_{h}-X_{m} \beta_{m}\right)-\left(v_{h}-v_{m}\right)-\left(\hat{\gamma}_{h} \lambda_{h}-\hat{\gamma}_{m} \lambda_{m}\right)
$$

Por lo tanto la descomposición de la brecha salarial entre hombres y mujeres es explicada por el efecto características y el efecto remuneración a través del método de Oaxaca Blinder controlando por sesgo de selección, esta diferencia difiere a la estimación de la

\footnotetext{
${ }^{20}$ Debido a que se controlan las diferencias en las características productivas.

${ }^{21}$ Cociente entre la función de densidad y la distribución normal estándar.
} 
brecha de los salarios observados, ya que los diferenciales promedio de las variable independientes difieren del diferencial salarial promedio de la variable dependiente (Neuman y Oaxaca, 2004).

$$
\hat{\Delta}_{w}-\left(\hat{\gamma}_{h} \lambda_{h}-\hat{\gamma}_{m} \lambda_{m}\right)=\underbrace{\left(\bar{X}_{h}-\bar{X}_{m}\right) \hat{\beta}_{h}}_{\text {Efecto carateristicas }}+\underbrace{\bar{X}_{m}\left(\hat{\beta}_{h}-\hat{\beta}_{m}\right)}_{\text {Efecto remuneración }}
$$

No obstante, si se quiere analizar la descomposición del diferencial salarial en la distribución incondicional (como los cuantiles) del ingreso laboral y saber que puede pasar con los efectos características y remuneración, es decir, poder aislar ambos efectos de la distribución no condicional, se utilizan en principio la regresión por cuantiles (quantile regression) y específicamente las metodologías de descomposición, desarrolladas por Machado y Mata (2004); Autor, Katz y Kearney (2005); Melly (2005) y Firpo, Fortin y Lemieux (2011). Sin embargo en este caso el método de Melly (2005) surge como alternativa para estimar los efectos características y remuneración en la distribución incondicional del salario, teniendo en cuenta el problema de sesgo por selección en el ingreso laboral de las mujeres.

La regresión por cuantiles desarrollada por Koenker y Bassett (1978) surge como alternativa para medir el efecto de un vector de variables explicativas en la variable explicada en diferentes puntos de la distribución condicional, debido a la presencia de heterocedasticidad en la distribución de variables que no puede ser capturada por las variables explicativas en la regresión lineal. "Esto hace necesario disponer de una estrategia empírica que permita explorar cualquier efecto de las variables explicativas en la variable explicada, sin recurrir al análisis de media o varianza" (Progreso en Econometría, 2005, p.107). El modelo de regresión por cuantiles permite caracterizar la distribución condicional de los salarios del $\theta$-esimo cuantil, con respecto a las variables explicativas o características observables de los individuos de la forma:

$$
Q_{w}(\theta \mid X)=X_{j} \beta(\theta)
$$


De tal manera que $Q_{w}(\theta \mid X)$ es la función cuantil y $\beta(\theta)$ es el vector de parámetros a estimar para cada $\theta$-esimo cuantil con $(0<\theta<1)$ de la distribución. Dado que el modelo es lineal en las variables explicativas, es decir, siguiendo nuestro análisis la regresión por cuantiles estima los retornos de las características observables del individuo para cada cuantil de la distribución del salario. Sin embargo este método tiene la misma debilidad de la regresión múltiple, la cual no corrige los problemas de endogeneidad ${ }^{22}$.

Por su parte, Melly (2005) plantea una alternativa de descomposición de la brecha salarial utilizando este método como base. Para ello propone un estimador no condicional que puede generarse al integrar la distribución condicional en todo el rango de la distribución de regresores. No obstante, cuenta con un problema de falta de monotonicidad, para evitar esto propone un cambio de variable en el proceso de integración, dado esto y siguiendo a Koenker y Bassett (1978) tenemos:

$$
F_{Y \mid X}^{-1}(\theta \mid X)=X_{j} \beta(\theta)
$$

Donde $F_{Y \mid X}^{-1}(\theta \mid X)$ es el $\theta$-esimo cuantil de $Y$ condicional sobre $X$. Como se sabe la relación lineal entre los cuantiles de $Y$ y $X$ es similar a la relación lineal entre las variables explicativas y explicada bajo Mínimos Cuadrado Ordinarios. Entonces al reemplazar $F_{Y \mid X}^{-1}(\theta \mid X)$ por su estimador consistente $X_{j} \beta(\theta)$ y tomando el ínfimo del conjunto de soluciones finitas sin que sea la única solución se obtiene:

$$
\hat{q}(\hat{\beta}, X)=\inf \left\{q: \frac{1}{N} \sum_{i=1}^{N} \sum_{j=1}^{J}\left(\theta_{j}-\theta_{j-1}\right) 1\left(X_{i} \beta(\theta) \leq q\right) \geq \tau\right\}
$$

Siendo $\hat{q}$ consistente y asintóticamente distribuido como una normal, por su parte la dificultad de estimar la varianza asintótica con lleva a utilizar el método de "Bootstrap" para hacer inferencia estadística.

\footnotetext{
${ }^{22}$ Chesler (2003), Koenker y Ma (2004) y Koenker (2005) plantean un sistema de ecuaciones triangulares para estimar el efecto marginal de la educación (incluyendo calidad educativa) utilizando variables instrumentales.
} 
La descomposición de los diferenciales en la distribución del salario para hombres y mujeres se realiza a partir de la distribución incondicional utilizando la regresión por cuantiles. Los estimadores obtenidos se utilizan para poder generar el ingreso contrafáctico en ambos género, ya que la idea principal de este estimador es la posibilidad de simular las distribuciones hipotéticas que se puedan utilizar para descomponer las diferencias en la distribución. Siguiendo la estructura de Jhon Murphy y Pierce (1993) se descompone el diferencial en la distribución de salario con una particularidad, se utiliza la mediana de la distribución como medida de tendencia central y se incluye en la ecuación, lo cual permite aislar los efectos características, remuneración y residual, cosa que no sucede con el método de JMP.

Para obtener el efecto en los cambios de las características, remuneración (incluyendo el efecto residual), se debe primero calcular la distribución contrafactual del salario de las mujeres y suponer que su distribución de sus características observables ha sido como la de los hombres. Entonces minimizando (11) para la distribución de los hombres y a través de los coeficientes estimados para las mujeres, formalmente se genera:

$$
\hat{q}\left(\beta_{m}, X_{m}\right)-\hat{q}\left(\beta_{h}, X_{h}\right)=\underbrace{\left[\hat{q}\left(\beta_{\text {mediam } r h}, X_{m}\right)-\hat{q}\left(\beta_{h}, X_{m}\right)\right]}_{\text {Efecto remuneración }}+\underbrace{\left[\hat{q}\left(\beta_{h}, X_{m}\right)-\hat{q}\left(\beta_{h}, X_{h}\right)\right]}_{\text {Effecto caracteristicas }}
$$

Para corregir por sesgo de selección en la distribución del salario horario se sigue a Buchinsky (1998), dado esto se utiliza la estimación paramétrica de la inversa del ratio de Mills y su valor cuadrado, los cuales se agregan como variables adicionales al método de descomposición del diferencial salarial por género propuesto por Melly (2005). Esto permitirá corregir el sesgo de selección debido el rol de madres de las mujeres en cada cuantil de la distribución salarial.

$$
\hat{q}\left(\beta_{m}^{\prime}, X_{m}^{\prime}\right)-\hat{q}\left(\beta_{h}^{\prime}, X_{h}^{\prime}\right)=\underbrace{\left[\hat{q}\left(\beta_{\text {mediam }, r h}^{\prime}, X_{m}^{\prime}\right)-\hat{q}\left(\beta_{h}^{\prime}, X_{m}^{\prime}\right)\right]}_{\text {Efecto remuneración }}+\underbrace{\left[\hat{q}\left(\beta_{h}^{\prime}, X_{m}^{\prime}\right)-\hat{q}\left(\beta_{h}^{\prime}, X_{h}^{\prime}\right)\right]}_{\text {Efecto caracteristicas }}
$$




\section{Resultados}

La tabla 4 muestra la descomposición Oaxaca - Blinder del salario horario promedio por género en Colombia durante el periodo de estudio. Como se puede observar la brecha bruta del salario laboral horario promedio disminuye en el tiempo, para el año 2004 esta fue de $14 \%$, con una variación promedio negativa de $-11 \%$, lo que con lleva a una brecha para el año 2012 de 11\%. Por su parte, el efecto características decrece con el paso de los años, siendo positivo únicamente para el año 2004 (1,6\%), puesto que para los años 2008 y 2012 fue de $-12 \%$ y $-17 \%$ respectivamente. Este resultado determina que en promedio la diferencia en las características productivas es a favor de las mujeres, es decir, los componentes que mejoran la productividad como es el caso de la educación es mayor en las mujeres con relación a los hombres.

Por su parte, el efecto remuneración que indica cual sería el diferencial salarial de las mujeres si fueran remuneradas como los hombres es positivo y creciente durante el periodo de estudio (13\% para 2004, 24\% para 2008 y 29\% para 2012), siendo mayor que la brecha total del ingreso laboral horario, lo cual hace que el efecto característica sea compensado haciendo que el diferencial salarial beneficie a los hombres.

La tabla 5 muestra la descomposición de la brecha salarial por género corrigiendo por sesgo de selección. Las estimaciones obtenidas muestran que el efecto característica en este caso es negativo y decreciente para todo los años analizados (-5\% en $2004,-23 \%$ en 2008 y $28 \%$ en 2012). Por su parte, el efecto remuneración sigue siendo creciente, sin embargo este es mayor con relación al modelo de OB sin corregir por sesgo de selección (20\% para 2004, 35\% para 2008 y 40\% para 2012). Estos resultados reflejan que existe una alta discriminación en contra de las mujeres y que esta se incrementan al incluir como instrumento una variable que influya en el tiempo de trabajo de las mujeres como es el caso de los hijos menores.

Por otro lado las tablas 6 a y 6 b presentan los resultados de la descomposición de los efectos características y remuneración luego de controlar por características personales (incluye educación y edad), tipos de trabajo (incluye los trabajadores en el sector privado, público, 
patrones, trabajadores domésticos y cuenta propia), y por último características regionales (incluye la regiones Atlántica, Central, Pacifica y Orinoquia).

Primero se puede observar que al descomponer el efecto características por cada uno de los componentes mencionados, se encuentra que solo el tipo de empleo (a excepción del año 2008 para el trabajo doméstico) contribuye positivamente en explicar este efecto; sin embargo es decreciente con el paso del tiempo para los tipos de empleo privado, público y cuenta propia. Por su parte, la educación es el único componente de las características personales que contribuyen negativamente en el efecto característica y siendo decreciente para todos los años analizados (-6,5\% en $2004,-13 \%$ en 2008 y $-15 \%$ en 2012). Esto puede deberse al hecho que las mujeres en Colombia con el pasar del tiempo han incrementado su educación. Las regiones en cambio contribuyen de diferente manera, para el año 2012 todas las regiones generan un resultado negativo en el efecto características; no obstante, es la región Atlántica la que siempre ha tenido una dirección de cambio negativa durante los años analizados. Así mismo, las regiones Central y Pacifica empezaron a tener un efecto negativo en el componente característica a partir del año 2008.

En cuanto a la descomposición del efecto remuneración se obtiene que las características personales (a excepción de la edad al cuadrado para los años 2008 y 2012) contribuyen positivamente con un rendimiento creciente durante el periodo de estudio ${ }^{23}$, pasando de tener el 3,5\% en 2004 a 3,6\% en 2012 para el componente de educación. Los demás componentes explican positivamente como negativamente el efecto remuneración, destacándose principalmente el trabajo público y doméstico, los cuales contribuyen negativamente durante los años analizados. Igualmente sucede con el componente de características regionales (exceptuando el año 2012 para las regiones Atlántica, Central y Orinoquia) aunque en mayor grado explica negativamente el efecto remuneración, siendo la región Pacifica con un componente del 8,1\% en 2004, -5,9\% en 2008 y -1,4\% en 2012 la que más contribuye en reducir el efecto remuneración.

Las tablas 7a y $7 \mathrm{~b}$ muestran la descomposición de los efectos características y remuneración corrigiendo por sesgo de selección, utilizando como instrumento la inversa

\footnotetext{
${ }^{23}$ Contribuyendo a que el diferencial salarial no explicado del salario este a favor del género masculino.
} 
de Mills. Los resultados obtenidos son poco robustos debido al cambio de signo de algunos componentes para cada efecto. Teniendo esto en cuenta, se encuentra que el efecto característica se explica principalmente por la educación como característica personal, con una variación negativa durante el periodo de estudio. Con relación a los tipos de empleo, el único trabajo que contribuye positivamente en todos los años analizados es cuenta propia, con un componente de $1,1 \%$ en $2004,4,2 \%$ en 2008 y $1 \%$ en 2012. Las regiones en cambio explican de diferente manera el efecto característica para el año 2004, solo la región Atlántica y Orinoquia contribuyeron negativamente, para el año 2012 solo la región Atlántica aporta positivamente en este efecto.

Por su parte, al descomponer el efecto remuneración corrigiendo por sesgo de selección, se encuentra que en las características personales solo la educación y la edad contribuyen negativamente en reducir este efecto, especialmente para el año 2012 con un componente de $-0,11 \%$ y $-1,20 \%$ respectivamente. Tipos de trabajo como el doméstico, cuenta propia y gobierno también influyen negativamente; sin embargo es el trabajo doméstico el que genera un efecto negativo para cada año analizado (-1,9\% en 2004, $-0,9 \%$ en 2008 y $-1,5 \%$ en 2012). Igualmente sucede con las regiones, todas contribuyeron en reducir el efecto remuneración, siendo la región Pacifica la que influyó negativamente durante todo el periodo de estudio.

Una vez controlado el efecto característica y remuneración por los distintos componentes se han encontrado dos resultados interesantes. En primer lugar, al analizar ambos efectos se encuentra que el diferencial salarial entre hombres y mujeres para el periodo de estudio se debe principalmente a factores (observables) que intervienen en la productividad del individuo, al descomponer estos efectos para cada componente se ha encontrado que las diferencias en factores como la educación, edad, tipo de trabajo y características regionales contribuyen en explicar la brecha salarial por género.

En segundo lugar, al estudiar profundamente el efecto remuneración se llega a la conclusión que este se ha incrementado (lo que puede explicar el incremento del diferencial salarial por género) con el paso del tiempo y que se debe a diferencias en las características personales de los individuos; sin embargo al corregir por sesgo de selección es la edad, 
algunos tipos de trabajo y regiones lo que explica positivamente este efecto. Cabe destacar que los resultados que se han obtenido generan un indicio de discriminación salarial en contra de las mujeres; sin embargo no se puede afirmar que para el año 2012 el 11\% del diferencial salarial es explicado por un efecto remuneración del 29\% y 40\% (corrigiendo por sesgo de selección), debido a que existe factores inobservables más allá de la discriminación salarial, ejemplo de ello, las habilidades innatas, calidad educativa, preferencias entre otras.

Los resultados obtenidos anteriormente presentan el diferencial salarial promedio entre hombres y mujeres, controlando por las características observables de los individuos. No obstante, al analizar la brecha salarial en toda la distribución de los salarios se puede encontrar diferencias significativas, ya que hasta ahora solo se ha realizado descomposiciones en la media de los salarios, siendo difícil evaluar o no el fenómeno de "Techos de Cristal", el cual evidencia una brecha salarial mayor por género para los percentiles más altos del ingreso laboral.

La tabla 8a muestra los resultados de la descomposición de la brecha salarial para los diversos cuantiles de la distribución del salario horario, utilizando la metodología de Melly (2005) explicada en la sección anterior, la inferencia fue llevada a cabo a través del método de remuestreo bootstrapping que permita generar los errores estándar de las distribuciones contrafactuales. Las columnas presentan la brecha bruta, efecto características y efecto remuneración controlando por características sociodemográficas, ocupacionales y regionales, por su parte cada fila determina los distintos cuantiles (q10, q25, q50, q75, q90) de la distribución del salario horario. Igualmente la tabla $8 \mathrm{~b}$ muestra el rango intercuantílico de la brecha bruta, el efecto característica y el efecto remuneración; así mismo las gráficas 4 y 5 presentan la brecha bruta, el efecto características y el efecto remuneración en función de los 100 percentiles de la distribución del salario horario.

Como se puede observar, existe un comportamiento creciente de la brecha bruta en la distribución de salario para cada año de estudio (véase tabla 4a), es decir a medida que los hombres se ubican en ingresos laborales más altos el diferencial salarial con respecto a las mujeres se incrementa. Al controlar por características sociodemográficas (educación y 
edad) y ocupacionales (trabajador privado, del gobierno, doméstico y cuenta propia) el diferencial salarial por género es mayor en los cuantiles más altos de la distribución del ingreso laboral correspondiente a cada uno de los años utilizados, es decir, se evidencia el fenómeno de "Techos de Cristal” en la población femenina. De igual manera al controlar por regiones (atlántica, pacifica, central y orinoquía) la brecha salarial por género se sigue comportando de la misma manera.

No obstante, si bien es cierto que la brecha salarial es creciente para los diferentes cuantiles de la distribución de salario horario, con el paso del tiempo se ha reducido con alguna variabilidad en los diferentes segmentos de la distribución. La brecha bruta de los individuos en la cola inferior de la distribución (cuantil 10) durante el año 2004 es de 25\%, en 2008 y 2012 fue $31 \%$ respectivamente. Con respecto a los individuos con mayores ingresos laborales (cuantil 90) los resultados varían, para el año 2004 la brecha observada es de 45\%, en 2008 fue 47\% y para el 2012 estuvo en alrededor del 42\%, este comportamiento se debe principalmente a los cambios en los efectos característica y remuneración.

El efecto característica ha tenido un comportamiento decreciente para los individuos con bajos (cuantil 10) y mayores (cuantil 90) ingresos en la distribución de salarios, para el año 2004 este fue de $7 \%$ y $20 \%$, en 2008 fue $2 \%$ y $20 \%$ y para 2012 fue $-9 \%$ y $12 \%$ respectivamente. En otras palabras para los intervalos con menores ingresos la diferencia entre las características productivas (educación) entre hombres y mujeres es menor con respecto a la cola superior de la distribución de los salarios.

El efecto remuneración, es importante debido a que explica el diferencial salarial en cada uno de los percentiles de la distribución del salario horario, debido a que este efecto incrementa la brecha bruta. Lo primero que se puede determinar es el comportamiento creciente del efecto remuneración para el año 2004 con un 18\% para los individuos con menores salarios (cuantil 10) y $25 \%$ para los individuos con mayores salarios (cuantil 90). En 2008 fue 29\% y 27\% para los individuos con menores y mayores ingresos, para 2012 estuvo alrededor de $40 \%$ para los individuos con salarios menores (cuantil 10) y 30\% para los individuos con elevados salarios (cuantil 90). 
La tabla 9a muestra la brecha bruta, el efecto característica y el efecto remuneración utilizando las metodologías de Melly (2005) y Buchinsky (1998) para corregir por sesgo de selección. De igual manera las gráficas 6 y 7 muestran la brecha bruta, el efecto características y el efecto remuneración en función de los todos los cuantiles de la distribución del salario horario, corrigiendo por sesgo de selección. Como se puede observar la brecha bruta no varía durante el periodo de estudio, los individuos con menores ingresos (cuantil 10) para el año 2004 tienen una diferencial de 25\%, para los años 2008 y 2012 la brecha es de 31\%. De igual manera sucede con los individuos de mayor ingreso laboral (cuantil 90), los cuales tienen una brecha bruta de $45 \%, 47 \%$ y $42 \%$ para los años 2004, 2008 y 2012 respectivamente.

Al incluir como instrumento la tenencia de hijos en el hogar, el efecto característica cambia para toda la distribución de salarios. Las estimaciones muestran que los individuos en la cola izquierda (cuantil 10) y derecha (cuantil 90) de la distribución de salarios, tienen un efecto de 5\% y 15\% para el año 2004, -6\% y 8\% en 2008 y -15\% y 3\% para 2012. Si bien este efecto sigue siendo creciente al pasar por los diferentes cuantiles del salario horario, al ser comparando con los resultados obtenidos anteriormente (tabla 8a) se evidencia una sobreestimación en el efecto característica al no haber controlado por sesgo de selección, una diferencia para los individuos con menores (cuantil 10) y mayores (cuantil 90) ingresos de $2 \%$ y $5 \%$ en $2004,8 \%$ y $12 \%$ en $2008,6 \%$ y $9 \%$ para el año 2012 respectivamente.

El efecto remuneración es creciente durante el periodo de estudio para cada uno de los percentiles de la distribución del salario horario. Las estimaciones muestran que los individuos con menor salario horario (cuantil 10) para el año 2004 tienen un efecto de 20\%, en 2008 es de $37 \%$ y 2012 llega al 46\%. Con respecto al 10\% de los hombres y mujeres con mayor salario (cuantil 90), el efecto remuneración para el 2004 es de 31\%, para el 2008 y 2012 alcanza una cifra de 39\% respectivamente. Los resultados obtenidos anteriormente determinan que la brecha salarial explicada por las diferencias en las remuneraciones de capital humano (incluida la discriminación salarial) de los hombres con relación a las mujeres disminuye si se tiene hijos menores en los hogares, siendo analizado anteriormente como el sobre costo en el salario de eficiencia de las mujeres. 
Por su parte, la tabla 8 b presenta el rango intercuantílico (cuantil 90 - cuantil 10) de la brecha bruta, efecto característica y remuneración durante el periodo de estudio. Las estimaciones muestran que la desigualdad en la brecha bruta ha disminuido, pasando de 19\% en el año 2004 a 11\% para el 2012, este resultado se debe especialmente al cambio del efecto remuneración con un valor para el año 2012 de -10\%. Sin embargo el componente explicado (efecto característica) durante el periodo analizado ha presentado un crecimiento de ocho puntos porcentuales, al pasar de $13 \%$ en el año 2004 a $21 \%$ para el 2012. Estos resultados determinan que en los últimos años la desigualdad en el diferencial salarial por género en Colombia ha disminuido, siendo explicado principalmente por la discrepancia en el efecto característica; no obstante las estimaciones también muestran que la desigualdad en el efecto remuneración es menor con el paso de los años, es decir, los individuos con menores ingresos laborales (cuantil 10) tiene una mayor remuneración del capital humano a favor de los hombres con respecto a los individuos situados en la derecha de la distribución del salario (cuantil 90), este comportamiento se incrementa con el paso del tiempo, a tal punto que el efecto remuneración es mayor en los individuos de menor salario horario.

Para finalizar al corregir por sesgo de selección la desigualdad en la brecha bruta, el efecto característica y el efecto remuneración durante el periodo de estudio (véase tabla 9b). La desigualdad en la brecha bruta se reduce en 12\%, al pasar de 19\% en 2004 a 7\% en 2012, de igual manera sucede con la discrepancia en el efecto remuneración, el cual durante el periodo disminuye 25\%, pasando de $9 \%$ en 2004 a -16\% para el año 2012. Por el contrario la desigualdad en el efecto característica presenta un crecimiento del 13\%, al pasar de $10 \%$ en 2004 a 23\% para el año 2012. Similarmente a los resultados anteriores la desigualdad en la brecha de salarios por género se reduce, y esto se debe principalmente a la disminución en la desigualdad del efecto remuneración, la única diferencia es que ahora al corregir por sesgo de selección la desigualdad en el efecto remuneración presenta una mayor variación negativa, de igual manera sucede con la desigualdad en el efecto característica, la cual en este caso se incrementa al incluir la tenencia de hijos menores en el hogar como variable de selección. 


\section{Conclusiones}

El presente estudio presenta evidencia sobre el diferencial salarial por género en Colombia durante el periodo 2004 - 2012. Los resultados obtenidos muestran que la brecha bruta ha disminuido con el paso del tiempo con una variación promedio negativa de $-11 \%$. Como era de esperarse en la literatura de diferencial salarial por género, el efecto remuneración (componentes no explicado) explica una parte mayor de la brecha bruta, siendo creciente a medida que pasa el tiempo. Por su parte, el efecto característica tiene un peso cada vez menor en explicar el diferencial salarial por género en Colombia, ya que con el paso de los años este es negativo, es decir, que en promedio la diferencia en las características productivas es a favor de las mujeres.

De igual manera utilizando como variable de selección la tenencia de hijos menores de 18 años en el hogar, con el propósito de estimar la inversa de Mills y corregir por sesgo de selección. Las estimaciones muestran que la brecha bruta promedio no cambia, sigue estando en favor de los hombres, aunque decrece con el paso del tiempo. El efecto característica del salario promedio sigue siendo negativo y decreciente para todos los años analizados. Por su parte, el efecto remuneración continua siendo positivo y creciente, aunque este es mayor con relación a las estimaciones sin corregir por sesgo de selección. Estos resultados reflejan que existe una alta discriminación en contra de las mujeres y que esta se incrementa al adicionar como instrumento una variable que intervenga en el tiempo de trabajo de las mujeres.

Al analizar la brecha bruta para toda la distribución de los salarios se encuentra que esta es creciente para los diferentes niveles de ingresos laborales en cada año de estudio, es decir, el diferencial salarial por género es mayor en los cuantiles más altos de la distribución del ingreso laboral, esto valida la hipótesis de la existencia de "Techos de Cristal" para la población femenina con respecto al ingreso laboral. Así mismo, al controlar por las características productivas y regionales se obtiene que el efecto característica ha tenido un comportamiento decreciente durante el periodo analizado, especialmente para los individuos con menores (cuantil 10) y mayores (cuantil 90) ingresos en la distribución de salarios, es decir, la diferencia en las características productivas para los intervalos con 
menores ingresos entre hombres y mujeres es menor con respecto a la cola superior de la distribución de los salarios. Por otro lado, el efecto remuneración es el componente que más explica el diferencial salarial en los diferentes puntos de la distribución del salario horario, ya que el efecto remuneración incrementa la brecha bruta, compensando el valor negativo del efecto característica.

En cuanto al corregir por sesgo de selección en la distribución del ingreso laboral, se encuentra que el efecto característica presenta un comportamiento decreciente con el paso del tiempo, sin embargo este efecto es menor con relación al efecto característica que no incluye la corrección por sesgo de selección, en otras palabras las mujeres con menores ingresos (cuantil 10) tienen mejores características productivas que los hombres (siendo negativo el efecto característica), en cambio en la cola derecha de la distribución del salario (cuantil 90) son los hombres los que poseen mayores característica de capital humano. Con respecto al efecto remuneración se determina que es creciente para cada uno de los años analizados; no obstante al compararse con el efecto remuneración sin corregir por sesgo de selección, se encuentra una subestimación, es decir, las diferencias en las remuneraciones de capital humano entre hombre y mujeres aumentan al corregir por sesgo de selección, siendo los individuos con menores ingresos (cuantil 10) los que presenta mayor diferencia.

Estos resultados sugieren que una política pública en educación e inclusión laboral (incluyendo educación infantil), sería adecuada para que las mujeres puedan dejar en cierta parte el rol de madre y pueda acceder al mercado laboral. Dado esto en los últimos años el gobierno nacional crea y aprueba la Ley 1496 de 2011, la cual tiene como objetivo garantizar la igualdad salarial entre hombres y mujeres, fijando los mecanismos necesarios para que dicha igualdad sea real. Tales políticas pueden ser útiles a la hora de combatir la discriminación laboral por género, especialmente en sociedades donde existen restricciones en el acceso a educación y oportunidades laborales.

Finalmente se debe establecer que siempre existirán problemas en la estimación en estos modelos, ya que existen problemas de medición y sesgo por variables omitidas no observables. Estos problemas afectan a la distribución del salario, lo cual determina que el efecto remuneración no se explique completamente por la discriminación salarial. No 
obstante, poder controlar por sesgo de selección es un avance para mejorar el análisis de esta problemática del mercado laboral.

\section{Referencias}

Abadía, L. (2005). "Discriminación Salarial por Sexo en Colombia: Un Análisis desde la Discriminación Estadística". Pontificia Universidad Javeriana, Bogotá. Documento electrónico no publicado.

Alejo, J. (2006). "Desigualdad salarial en el gran Buenos Aires: Una Aplicación de Regresión por Cuantiles en Microdescomposiciones“. Documento de Trabajo No 36. CEDLAS, UNLP, Argentina.

Anderson, D., Binder, M. \& Krause, K. (2003). "The Motherhood Wage Penalty Revisited: Experience, Heterogeneity, Work Effort, and Work Schedule Flexibility”. Industrial and Labor Relations Review, Vol. 56, No. 2, pp. 273-295.

Arrow, K. (1971). “The Theory of Discrimination”. Industrial Relations Section Working Paper, No. 30A. Princeton University.

Asociación Argentina de Economía Política. (2005). "Progresos en Econometría". Buenos Aries.

Autor, D., Katz, L. \& Kearney, M. (2005). "Rising Wage Inequality: The Role of Composition and Prices”. NBER Working Paper, No. 11628.

Becker, G. (1971). The Economics of Discrimination. Chicago: University of Chicago Press.

Becker, G. (1985). "Human Capital, Effort, and the Sexual Division of Labor". Journal of Labor Economics, Vol. 3, No. 1, pp. 33-58.

Blau, F. (1996). "Where are we in the Economics of Gender? The Gender Pay Gap". NBER Working Paper Series, No. 5664.

Blinder, A. (1973). "Wage discrimination: reduced form and structural estimates." Journal of Human Resources, Vol. 8, No. 4, pp. 436-455.

Buchinsky, M. (1998). "Recent Advances in Quantile Regression Models: A Practical Guideline for Empirical Research.” The Journal of Human Resources, Vol. 33, No. 1, pp. $88-126$. 
Barrientos, J. \& Gaviria, A. (2001). "Determinantes de la Calidad de la Educación en Colombia". Archivos de Economía, No. 159, Departamento Nacional de Planeación, Bogotá.

Bérgolo, M. \& Carbajal, F. (2006). "Brecha Urbano - Rural de Ingresos Laborales en Uruguay para el año 2006: Una Descomposición por Cuantiles”. Documento de Trabajo, No 75. CEDLAS, UNLP, Argentina.

Cepeda, L. \& Barón, J. (2012). "Segregación Educativa y la Brecha Salarial por Género entre los Recién Graduados Universitarios en Colombia”. Documentos de Trabajo sobre Economía Regional, ISSN 1692-3715. Centros de Estudios Económicos Regionales (CEER), Banco de la República, Colombia.

Departamento Administrativo Nacional de Estadística . (2012). "Metodología Gran Encuesta Integrada de Hogares”. Bogotá, D.C.

Farfán, M. \& Ruiz, M. (2007). "Discriminación Salarial en la Argentina: Un Análisis Distributivo". Documento de Trabajo, No 60. CEDLAS, UNLP, Argentina.

Fernandez, M. (2006). "Determinantes del Diferencial Salarial por Género en Colombia". Documento CEDE, No. 2006-32, Universidad de Los Andes, Bogotá.

Flórez, C. (2004). "La Transformación de los Hogares: Una Visión de Largo Plazo". Revista Coyuntura Social, No. 30, pp. 23-49.

Fortin, N., Lemieux, T. \& Firpo, S. (2011). "Decomposition Methods in Economics". NBER Working Paper, No. 16045.

Goldin, C. \& Rouse, C. (2000). "Orchestrating Impartiality: The Impact of Blind Auditions on Female Musicians”. American Economic Review, Vol. 90, No. 4, pp. 715-741.

Galvis. L. (2010). "Diferenciales salariales por género y región en Colombia: Una aproximación con regresión por Cuantiles”. Documentos de trabajo sobre Economía Regional, No. 131, Banco de la República.

Heckman, J. (1979). "Sample Selection Bias as a Specification Error”. Econometrica, Vol. 47, No. 1, pp. 153-161.

Koenker, R. \& Bassett, J. (1978). "Regression Quantiles”. Econometrica, Vol. 46, No. 1, pp. 33-50.

Koenker, R. \& Hallock, K. (2001). “Quantile Regression”. Journal of Economic Perspectives, Vol. 15, No. 4, pp. 143-156. 
Machado J. \& Mata, J. (2005). "Counterfactual Decomposition of Changes in Wage Distributions Using Quantile Regression.” Journal of Applied Econometrics, Vol. 20, No. 4, pp. 445-465.

Mincer, J. \& Polacheck, S. (1974). "Family Investments in Human Capital: Earnings of Women”. Journal of Political Economy, Vol. 82, pp. 76-108.

Mincer, J. \& Ofek, H. (1980). “Interrupted Work Carrers”. NBER Working Paper Series, No. 479.

Neuman, S. \& Oaxaca, R. (2004). "Wage decompositions with selectivitycorrected wage equations: A methodological note.” Journal of economic inequality, Vol. 2, pp. 3-10.

Nguyen, B., Albrecht, J., Vroman, S., \& Westbrook, D. (2005). “A Quantile Regression Decomposition of Urban Rural Inequality in Vietnam."

Oaxaca, R. (1973). "Male - Female Wage Differentials in Urban Labor Markets". International Economics Review, Vol. 14, No. 3, pp. 693-709

O’Neill J. \& O’Neill, D. (2005). "What do Wage Differentials tell us About Market Discrimination?” NBER Working Paper Series, No. 11240.

Phelps, E. (1972). "The Statistical Theory of Racism and Sexism." American Economic Review, Vol. 62, No.4, pp.: 659-661.

Ribero, R. \& Meza, C. (1997). "Ingresos laborales de hombres y mujeres en Colombia: 1976-1995”. Archivos de Macroeconomía, No. 62, Departamento Nacional de Planeación, Bogotá.

Ribero, R., Tenjo, J. \& Bernat, L. (2005). “Evolución de las Diferencias Salariales por Sexo en seis países de América Latina: Un Intento de Interpretación”. Documento CEDE, No. 2005-18, Universidad de Los Andes, Bogotá.

Sistema de Indicadores Sociodemográficos SISD- Departamento Nacional de Planeación.

Tenjo, J. (1993). “1976-1989: Cambios en los diferenciales salariales entre hombres y mujeres". Planeación y Desarrollo, Vol. 24, pp. 103-116.

Waldfogel, J. (1998. "Understanding the Family Gap in Pay for Women with Children". Journal of Economics Perspectives, Vol. 12, No. 1, pp. 137-156. 


\section{Anexos}

\section{Gráfica 1. Proyección de la proporción poblacional por género.}

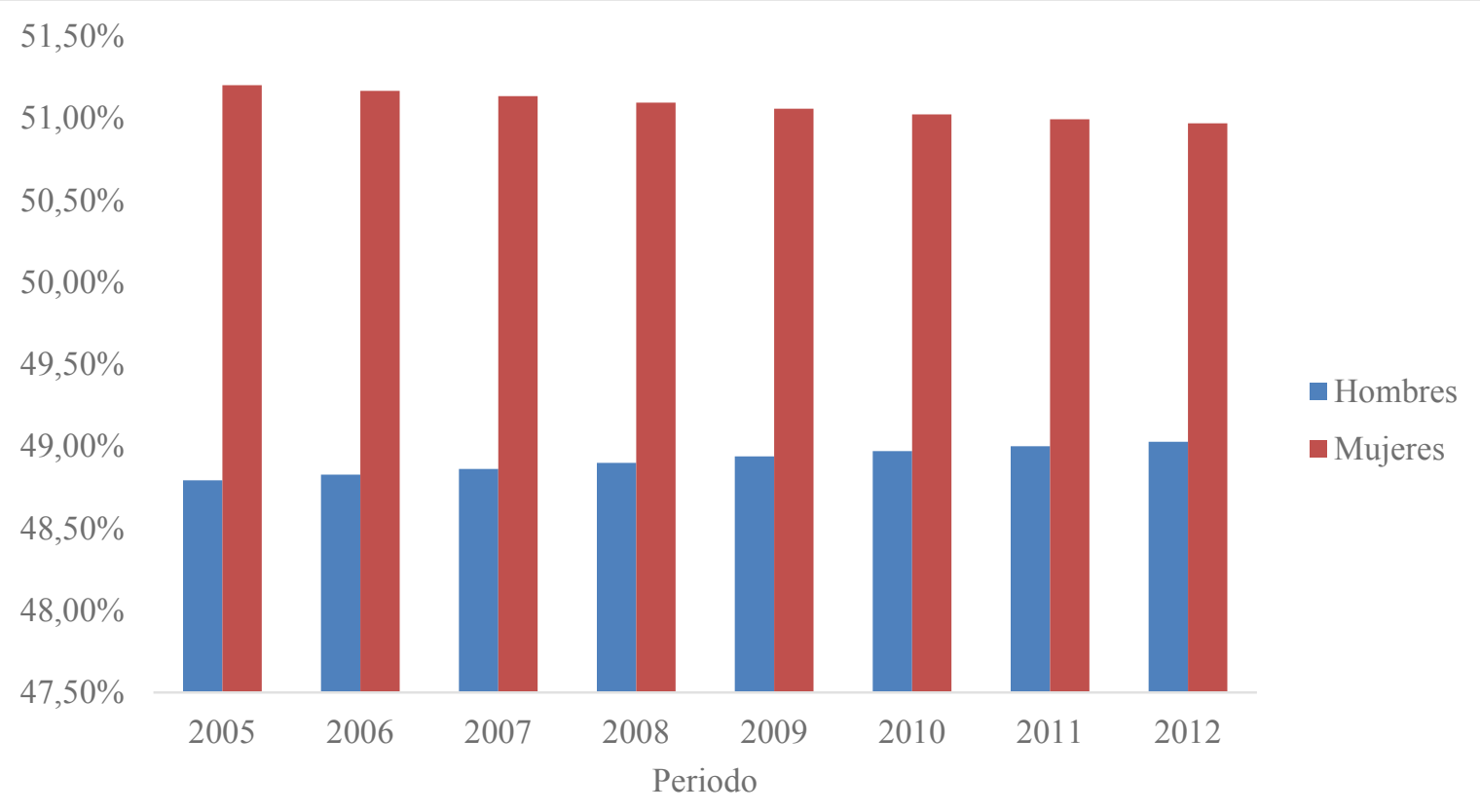

Nota: Población entre 15 y 69 años de edad. Datos expandidos con proyecciones de población, elaboradas con base en los resultados del censo 2005.

Fuente: Elaboración propia con base en las proyecciones de población del Departamento Administrativo Nacional de Estadística - DANE. 
Gráfica 2. Tasa global de participación laboral utilizando el último trimestre móvil (diciembre - febrero) para hombres y mujeres.

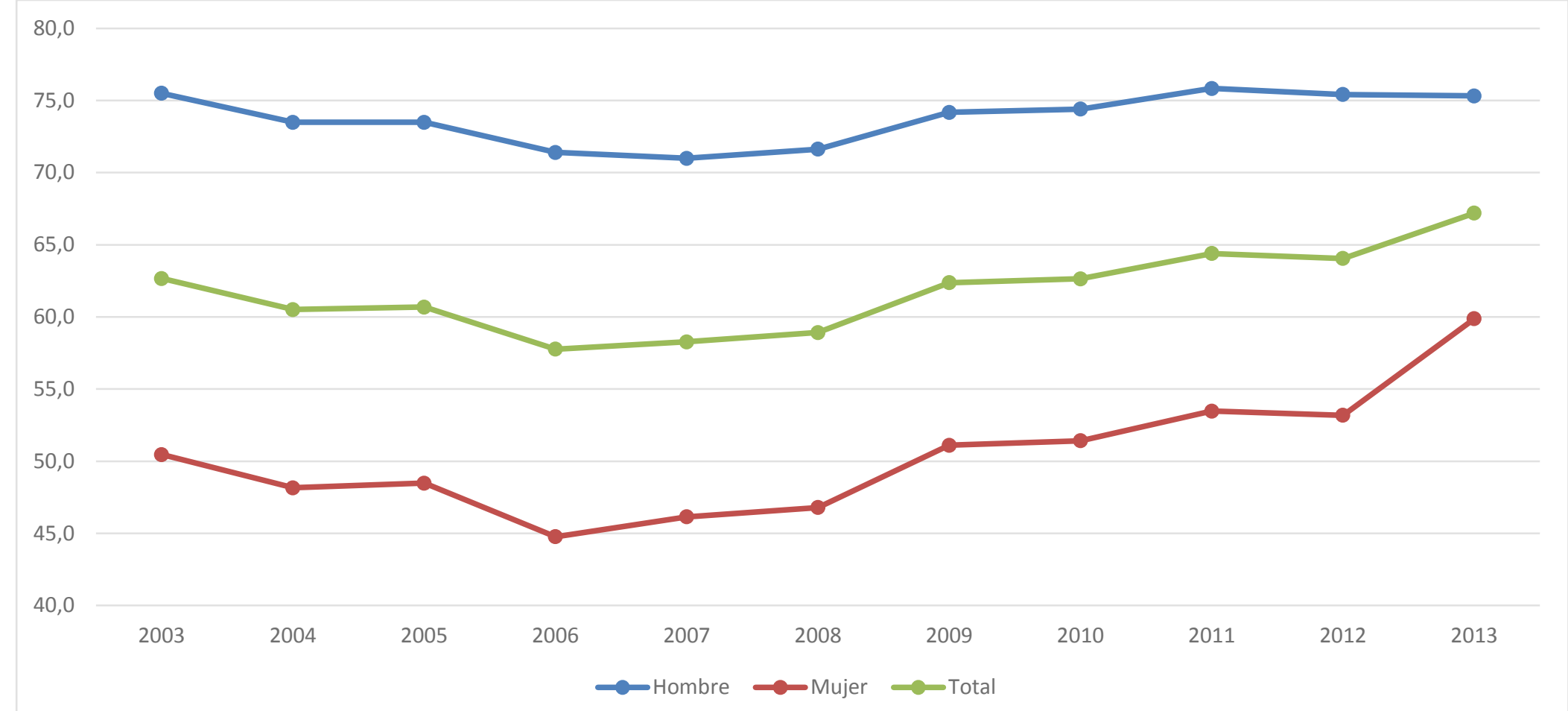

Fuente: Elaboración propia con base en la ECH -Gran Encuesta Integrada de Hogares, Departamento Administrativo Nacional de Estadística - DANE. 


\section{Gráfica 3. Funciones de densidad del logaritmo natural del salario horario para hombres y mujeres.}
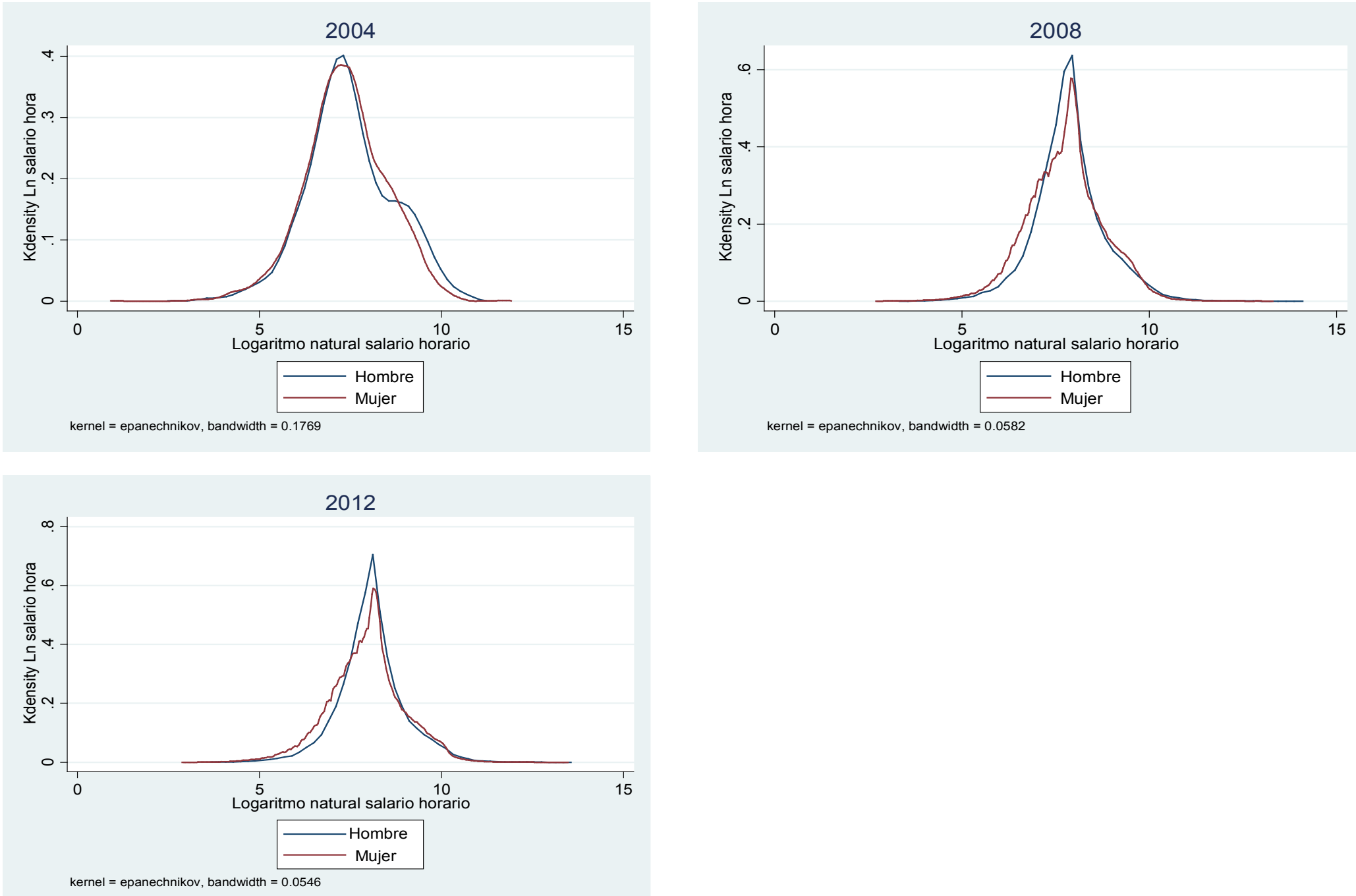

Nota: Individuos entre 18 y 65 años con ingresos laborales positivos.

Fuente: Elaboración propia con base en las encuestas del programa MESEP - DANE. 
Gráfica 4. Brecha bruta, efecto características y efecto remuneración por cuantiles de ingreso, controlando por características sociodemográficas, ocupacionales y regionales.
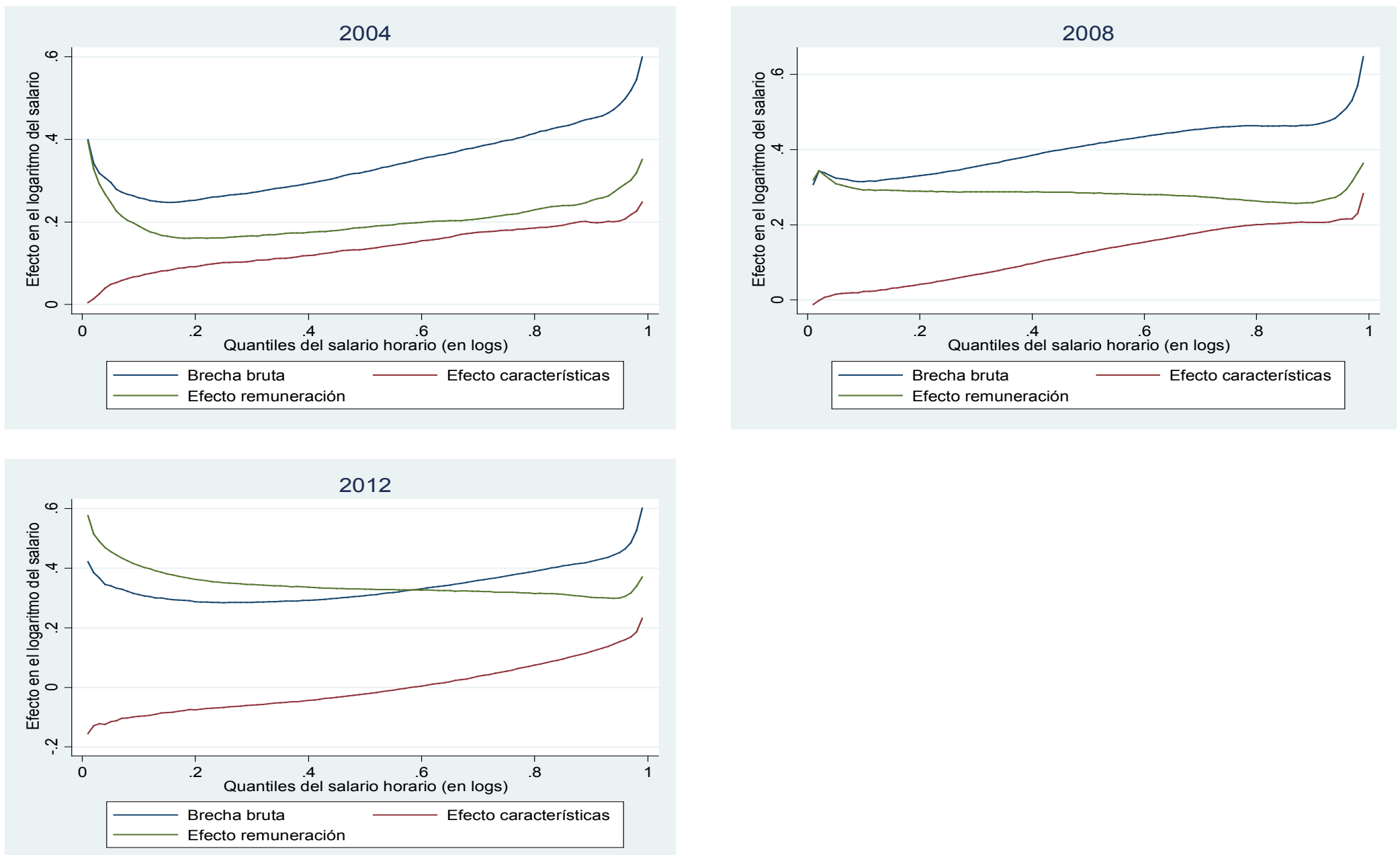

Nota: Individuos entre 18 y 65 años con ingresos laborales positivos.

Fuente: Elaboración propia con base en las encuestas del programa MESEP - DANE. 
Gráfica 5. Efecto remuneración por cuantiles de ingreso, controlando por características sociodemográficas, ocupacionales y regionales.
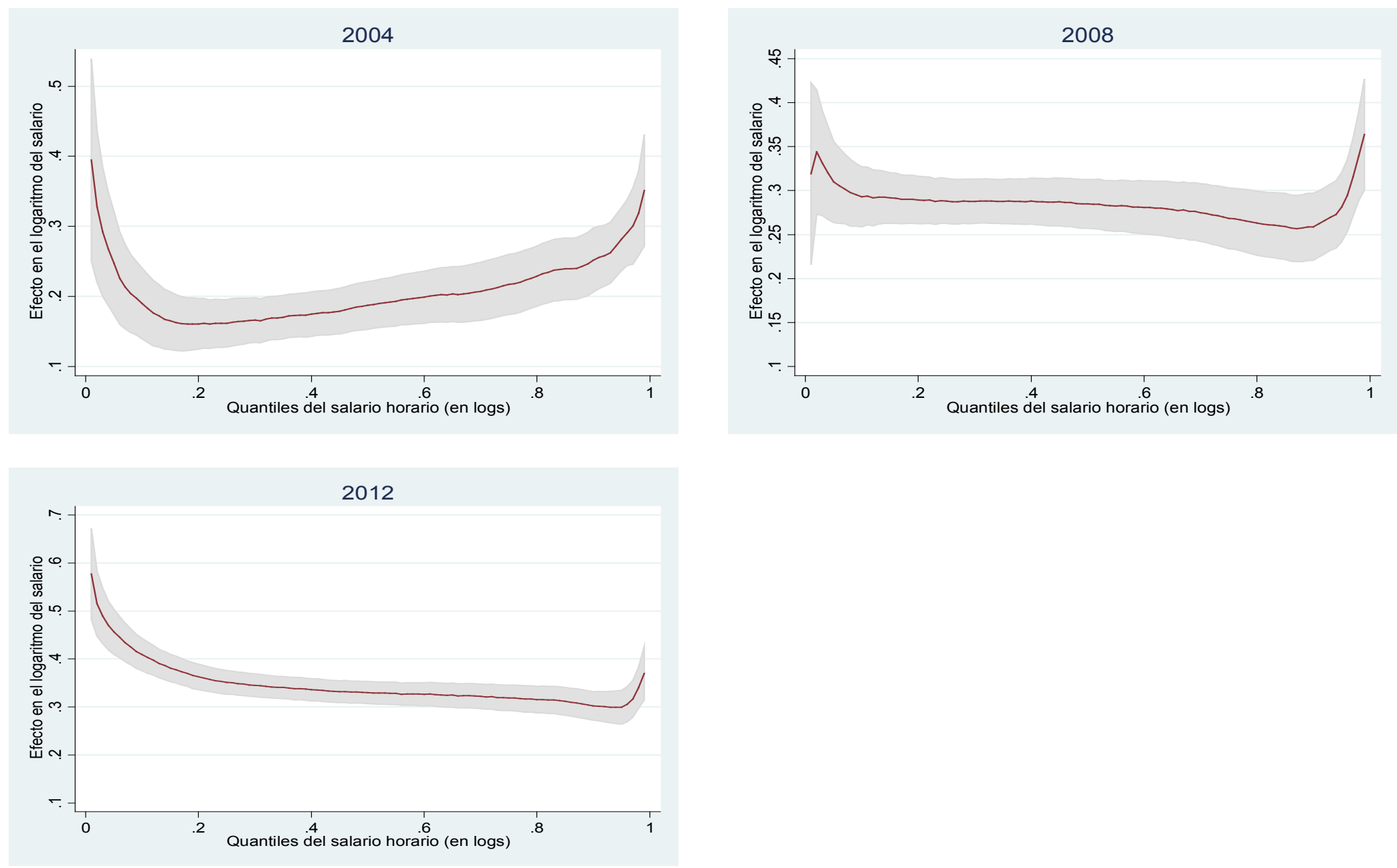

Nota: Individuos entre 18 y 65 años con ingresos laborales positivos.

Fuente: Elaboración propia con base en las encuestas del programa MESEP - DANE. 
Gráfica 6. Brecha bruta, efecto características y efecto remuneración por cuantiles de ingreso, controlando por características sociodemográficas, ocupacionales y regionales, con corrección por sesgo de selección.
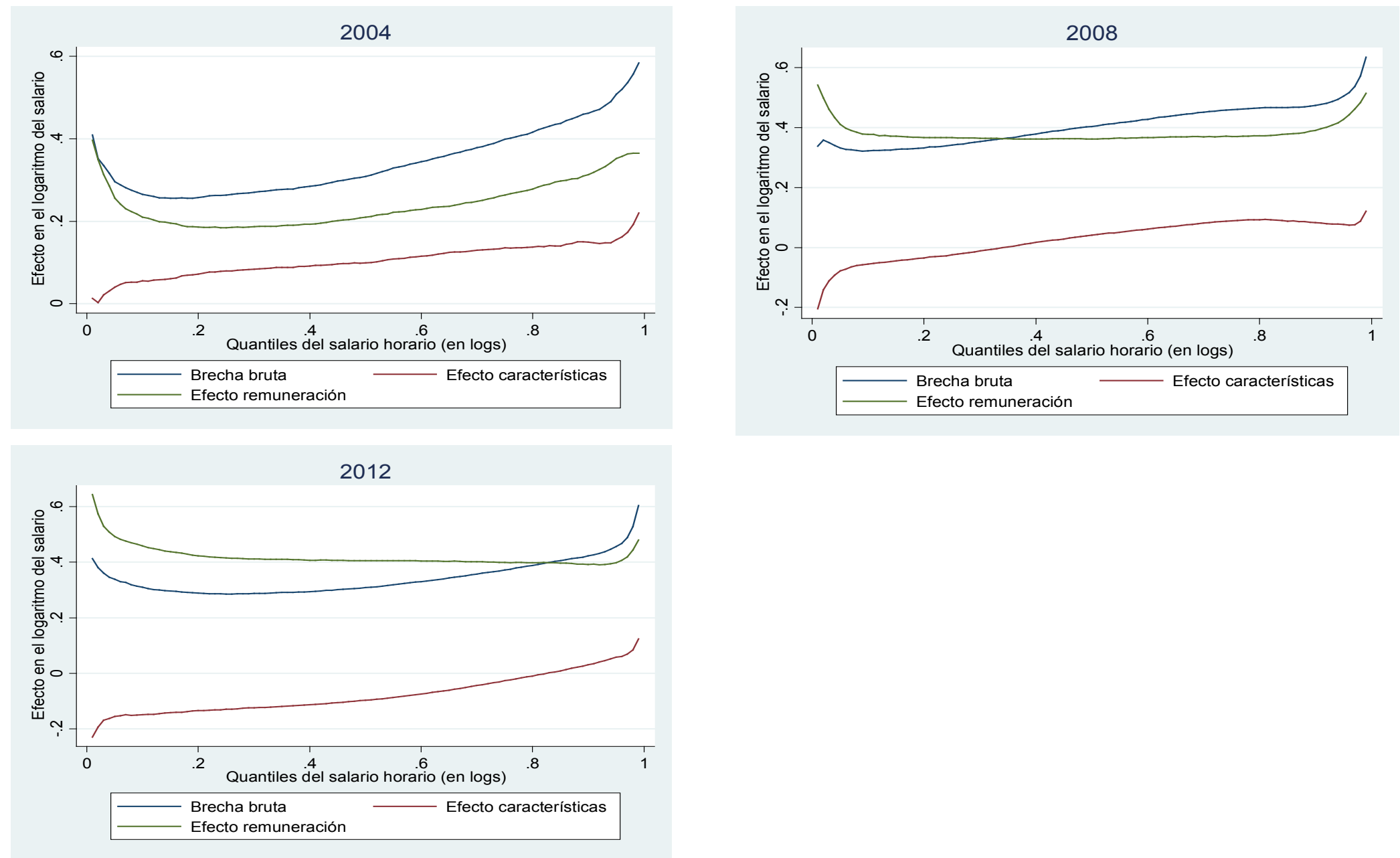

Nota: Individuos entre 18 y 65 años con ingresos laborales positivos.

Fuente: Elaboración propia con base en las encuestas del programa MESEP - DANE. 
Gráfica 7. Efecto remuneración por cuantiles de ingreso, controlando por características sociodemográficas, ocupacionales y regionales, con corrección por sesgo de selección.
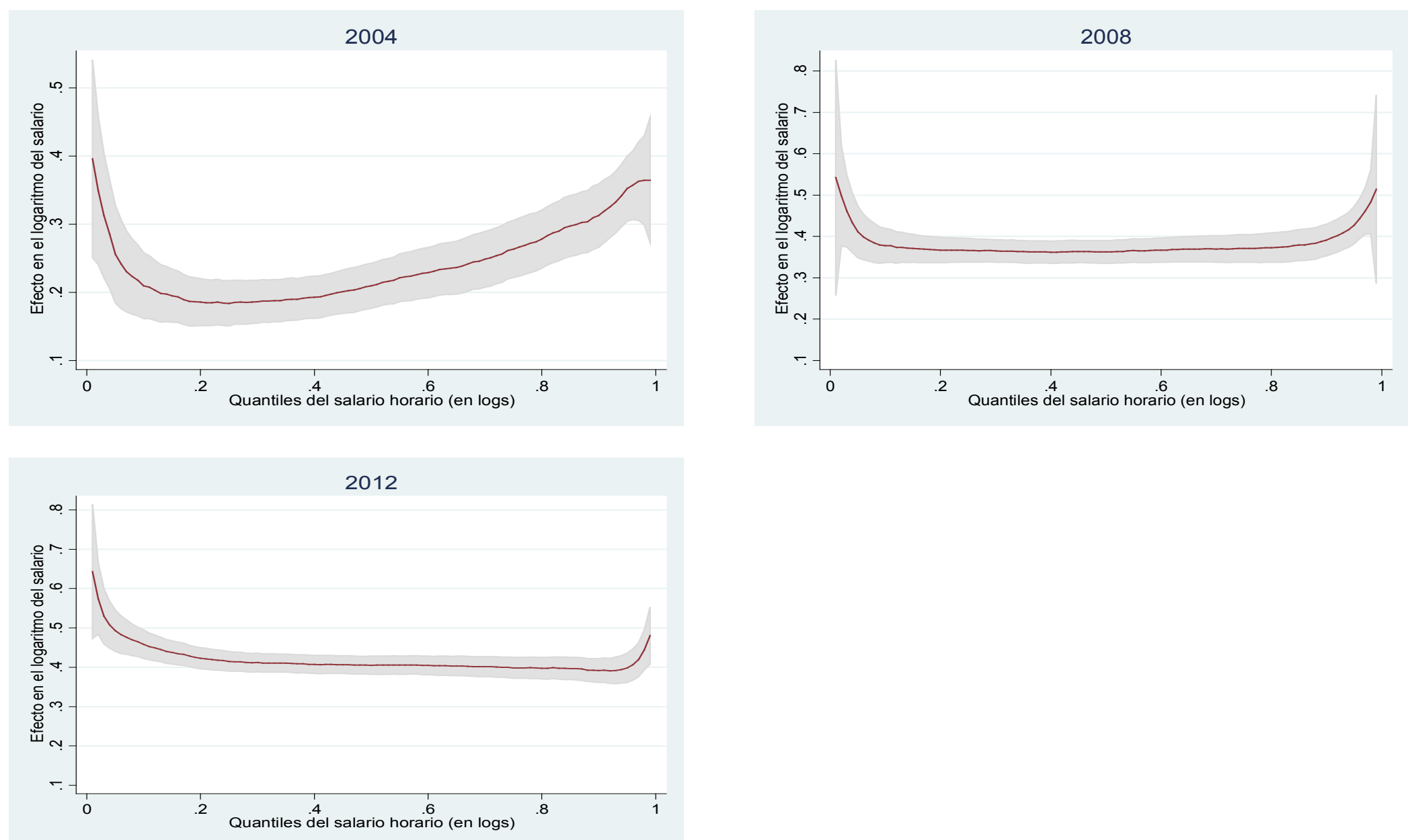

Nota: Individuos entre 18 y 65 años con ingresos laborales positivos.

Fuente: Elaboración propia con base en las encuestas del programa MESEP - DANE. 
Tabla 1a. Salario horario promedio por género y nivel educativo.

\begin{tabular}{|c|c|c|c|c|c|c|c|c|c|}
\hline & \multicolumn{3}{|c|}{2004} & \multicolumn{3}{|c|}{2008} & \multicolumn{3}{|c|}{2012} \\
\hline & Mujeres & Hombres & Diferencia & Mujeres & Hombres & Diferencia & Mujeres & Hombres & Diferencia \\
\hline \multicolumn{10}{|l|}{ Total } \\
\hline Salario horario promedio & $4.168,0$ & $5.435,0$ & $23,3 \%$ & $4.269,6$ & $5.498,4$ & $22,3 \%$ & $4.025,8$ & $4.892,8$ & $17,7 \%$ \\
\hline Quantil 10 & 358,4 & 410,1 & $12,6 \%$ & 568,1 & 604,8 & $6,1 \%$ & 558,9 & 658,0 & $15,1 \%$ \\
\hline Quantil 50 & $1.602,9$ & $1.870,1$ & $14,3 \%$ & $2.169,1$ & $2.325,5$ & $6,7 \%$ & $2.171,9$ & $2.224,6$ & $2,4 \%$ \\
\hline Quantil 90 & $9.662,2$ & $15.584,3$ & $38,0 \%$ & $10.500,0$ & $13.888,8$ & $24,4 \%$ & $9.146,5$ & $11.560,2$ & $20,9 \%$ \\
\hline R. intercuantílico (90-10) & $9.303,8$ & $15.174,2$ & $38,7 \%$ & $9.931,9$ & $13.284,0$ & $25,2 \%$ & $8.587,6$ & $10.902,2$ & $21,2 \%$ \\
\hline R. intercuantílico (90-50) & $8.059,3$ & $13.714,2$ & $41,2 \%$ & $8.330,9$ & $11.563,3$ & $28,0 \%$ & $6.974,6$ & $9.335,6$ & $25,3 \%$ \\
\hline R. intercuantílico (50-10) & $1.244,5$ & $1.460,0$ & $14,8 \%$ & $1.601,0$ & $1.720,7$ & $7,0 \%$ & $1.613,0$ & $1.566,6$ & $-3,0 \%$ \\
\hline \multicolumn{10}{|l|}{ Básica Primaria } \\
\hline Salario horario promedio & $1.382,0$ & $1.435,4$ & $3,7 \%$ & $1.493,2$ & $1.852,0$ & $19,4 \%$ & $1.686,8$ & $1.841,7$ & $8,4 \%$ \\
\hline Quantil 10 & 257,1 & 216,4 & $-18,8 \%$ & 390,6 & 425,0 & $8,1 \%$ & 398,1 & 490,3 & $18,8 \%$ \\
\hline Quantil 50 & 935,0 & 900,0 & $-3,9 \%$ & $1.181,8$ & $1.250,0$ & $5,5 \%$ & $1.341,4$ & $1.419,5$ & $5,5 \%$ \\
\hline Quantil 90 & $3.116,8$ & $2.857,1$ & $-9,1 \%$ & $2.857,1$ & $3.298,6$ & $13,4 \%$ & $3.241,9$ & $3.353,7$ & $3,3 \%$ \\
\hline R. intercuantílico (90-10) & $2.859,7$ & $2.640,7$ & $-8,3 \%$ & $2.466,5$ & $2.873,6$ & $14,2 \%$ & $2.843,8$ & $2.863,4$ & $0,7 \%$ \\
\hline R. intercuantílico (90-50) & $2.181,8$ & $1.957,1$ & $-11,5 \%$ & $1.675,3$ & $2.048,6$ & $18,2 \%$ & $1.900,5$ & $1.934,2$ & $1,7 \%$ \\
\hline R. intercuantílico (50-10) & 677,9 & 683,6 & $0,8 \%$ & 791,2 & 825,0 & $4,1 \%$ & 943,3 & 929,2 & $-1,5 \%$ \\
\hline
\end{tabular}

Nota: Individuos entre 18 y 65 años con ingresos laborales positivos. El nivel educativo básica primaria incluye los individuos con preescolar y primaria (1 grado -5 grado), el nivel educativo media incluye los individuos con secundaria ( 6 grado - 9 grado) y educación media (10 grado - 11 grado), y el nivel educativo contiene los individuos con educación universitaria o superior.

Fuente: Elaboración propia con base en las encuestas del programa MESEP - DANE. 
Tabla 1b. Salario promedio por género y nivel educativo (continuación).

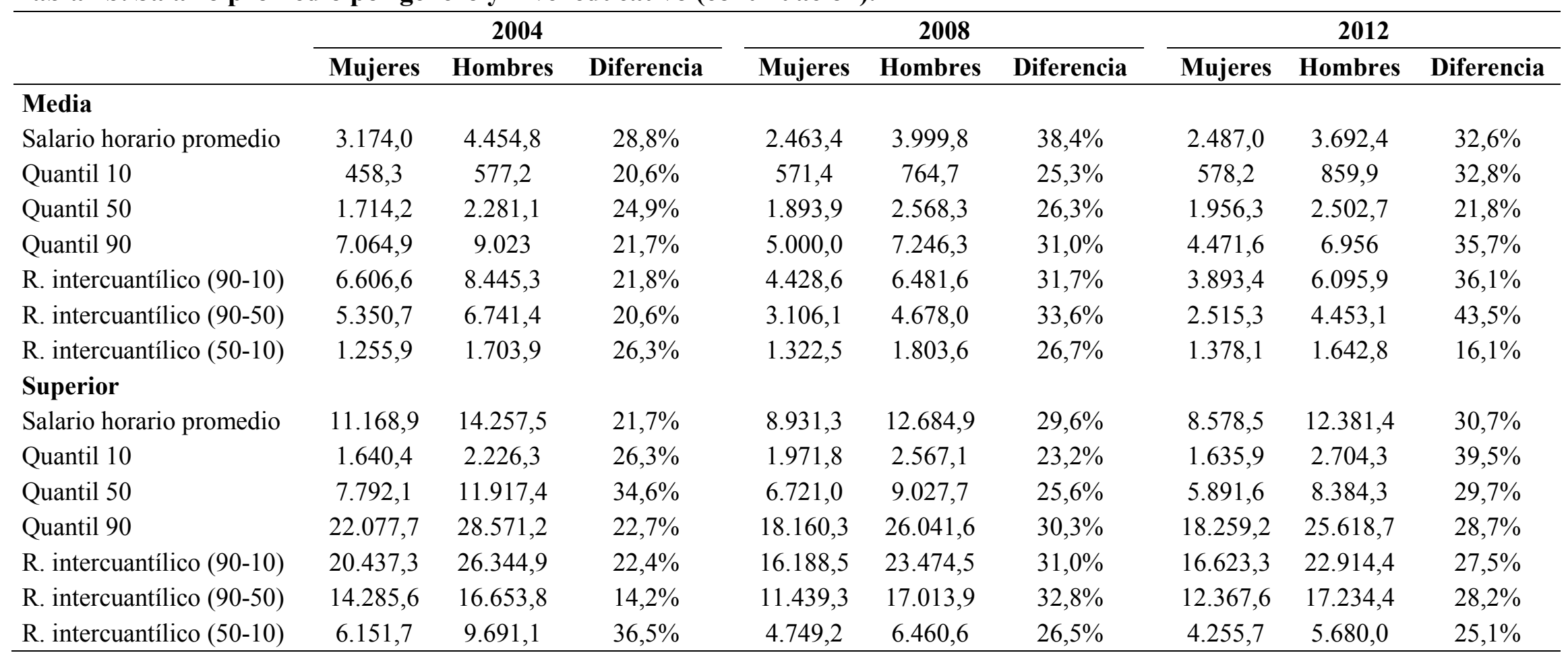

Nota: Individuos entre 18 y 65 años con ingresos laborales positivos. El nivel educativo básica primaria incluye los individuos con preescolar y primaria (1 grado - 5 grado), el nivel educativo media incluye los individuos con secundaria (6 grado - 9 grado) y educación media (10 grado - 11 grado), y el nivel educativo contiene los individuos con educación universitaria o superior.

Fuente: Elaboración propia con base en las encuestas del programa MESEP - DANE. 
Tabla 3a. Estadísticas descriptivas.

\begin{tabular}{|c|c|c|c|c|c|c|}
\hline & \multicolumn{2}{|c|}{2004} & \multicolumn{2}{|c|}{2008} & \multicolumn{2}{|c|}{2012} \\
\hline & Mujeres & Hombres & Mujeres & Hombres & Mujeres & Hombres \\
\hline \multicolumn{7}{|l|}{ Características personales } \\
\hline \multirow[t]{2}{*}{ Educación (en años) } & 9,38 & 8,55 & 9,70 & 8,26 & 9,74 & 8,48 \\
\hline & $(4,62)$ & $(4,62)$ & $(4,71)$ & $(4,78)$ & $(4,71)$ & $(4,74)$ \\
\hline \multirow[t]{2}{*}{ Edad } & 36,59 & 37,06 & 37,53 & 37,85 & 38,17 & 38,08 \\
\hline & $(11,25)$ & $(11,87)$ & $(11,36)$ & $(11,93)$ & $(11,81)$ & $(12,30)$ \\
\hline \multirow[t]{2}{*}{ Tiene hijos menores de 18 años $(1=$ si $)$} & 0,20 & 0,21 & 0,20 & 0,20 & 0,18 & 0,21 \\
\hline & $(0,40)$ & $(0,41)$ & $(0,40)$ & $(0,40)$ & $(0,39)$ & $(0,40)$ \\
\hline \multicolumn{7}{|l|}{ Tipos de trabajo } \\
\hline \multirow[t]{2}{*}{ Privado } & 0,37 & 0,39 & 0,39 & 0,39 & 0,38 & 0,40 \\
\hline & $(0,48)$ & $(0,48)$ & $(0,48)$ & $(0,48)$ & $(0,48)$ & $(0,49)$ \\
\hline \multirow[t]{2}{*}{ Gobierno } & 0,08 & 0,05 & 0,07 & 0,04 & 0,05 & 0,04 \\
\hline & $(0,27)$ & $(0,22)$ & $(0,26)$ & $(0,21)$ & $(0,22)$ & $(0,19)$ \\
\hline \multirow[t]{2}{*}{ Domestico } & 0,12 & 0,03 & 0,10 & 0,07 & 0,09 & 0,06 \\
\hline & $(0,33)$ & $(0,06)$ & $(0,30)$ & $(0,26)$ & $(0,29)$ & $(0,24)$ \\
\hline \multirow[t]{2}{*}{ Patrón } & 0,02 & 0,05 & 0,02 & 0,05 & 0,03 & 0,06 \\
\hline & $(0,15)$ & $(0,22)$ & $(0,16)$ & $(0,23)$ & $(0,16)$ & $(0,23)$ \\
\hline \multirow[t]{2}{*}{ Cuenta propia } & 0,38 & 0,41 & 0,39 & 0,42 & 0,43 & 0,42 \\
\hline & $(0,48)$ & $(0,49)$ & $(0,48)$ & $(0,49)$ & $(0,49)$ & $(0,49)$ \\
\hline \multirow[t]{2}{*}{ Asalariado } & 0,61 & 0,55 & 0,60 & 0,57 & 0,56 & 0,57 \\
\hline & $(0,48)$ & $(0,49)$ & $(0,48)$ & $(0,49)$ & $(0,49)$ & $(0,49)$ \\
\hline
\end{tabular}

Nota: Individuos entre 18 y 65 años con ingresos laborales positivos.

Fuente: Elaboración propia con base en las encuestas del programa MESEP - DANE. 
Tabla 3b. Estadísticas descriptivas (continuación).

\begin{tabular}{|c|c|c|c|c|c|c|}
\hline & \multicolumn{2}{|c|}{2004} & \multicolumn{2}{|c|}{2008} & \multicolumn{2}{|c|}{2012} \\
\hline & Mujeres & Hombres & Mujeres & Hombres & Mujeres & Hombres \\
\hline \multicolumn{7}{|c|}{ Características regionales } \\
\hline \multirow[t]{2}{*}{ Atlántica } & 0,18 & 0,24 & 0,15 & 0,19 & 0,17 & 0,20 \\
\hline & $(0,39)$ & $(0,43)$ & $(0,36)$ & $(0,39)$ & $(0,38)$ & $(0,40)$ \\
\hline \multirow[t]{2}{*}{ Central } & 0,55 & 0,50 & 0,58 & 0,54 & 0,58 & 0,54 \\
\hline & $(0,49)$ & $(0,50)$ & $(0,49)$ & $(0,49)$ & $(0,49)$ & $(0,49)$ \\
\hline \multirow[t]{2}{*}{ Pacifica } & 0,20 & 0,19 & 0,19 & 0,19 & 0,18 & 0,18 \\
\hline & $(0,40)$ & $(0,39)$ & $(0,39)$ & $(0,39)$ & $(0,38)$ & $(0,39)$ \\
\hline \multirow[t]{2}{*}{ Orinoquia } & 0,02 & 0,03 & 0,02 & 0,03 & 0,02 & 0,03 \\
\hline & $(0,15)$ & $(0,16)$ & $(0,15)$ & $(0,17)$ & $(0,15)$ & $(0,17)$ \\
\hline Observaciones & 319.720 & 288.864 & 438.096 & 385.718 & 430.527 & 382.184 \\
\hline
\end{tabular}

Nota: Individuos entre 18 y 65 años con ingresos laborales positivos.

Fuente: Elaboración propia con base en las encuestas del programa MESEP - DANE. 
Tabla 4. Brecha bruta. Descomposición de Oaxaca - Blinder.

\begin{tabular}{lccc}
\hline & $\mathbf{2 0 0 4}$ & $\mathbf{2 0 0 8}$ & $\mathbf{2 0 1 2}$ \\
\hline Brecha bruta & $0,14^{* * *}$ & $0,12^{* * *}$ & $0,11^{* * *}$ \\
& $(0,0033)$ & $(0,026)$ & $(0,0018)$ \\
Efecto características & $0,016^{* * *}$ & $-0,12^{* * *}$ & $-0,17 * * *$ \\
& $(0,0032)$ & $(0,019)$ & $(0,0013)$ \\
Efecto remuneración & $0,13 * * *$ & $0,24 * * *$ & $0,29 * * *$ \\
& $(0,0031)$ & $(0,019)$ & $(0,014)$ \\
\hline
\end{tabular}

Nota: ${ }^{*} \mathrm{p}<0,1 ; * * \mathrm{p}<0,05 ; * * * \mathrm{p}<0,01$. Individuos entre 18 y 65 años con ingresos laborales positivos.

Fuente: Elaboración propia con base en las encuestas del programa MESEP - DANE.

Tabla 5. Brecha bruta. Descomposición de Oaxaca - Blinder con corrección por sesgo de selección.

\begin{tabular}{lccc}
\hline & $\mathbf{2 0 0 4}$ & $\mathbf{2 0 0 8}$ & $\mathbf{2 0 1 2}$ \\
\hline Brecha bruta & $0,14^{* * *}$ & $0,12^{* * *}$ & $0,11^{* * *}$ \\
& $(0,0033)$ & $(0,0026)$ & $(0,0018)$ \\
Efecto características & $-0,051^{* * *}$ & $-0,23 * * *$ & $-0,28 * * *$ \\
& $(0,0036)$ & $(0,0033)$ & $(0,0029)$ \\
Efecto remuneración & $0,20 * * *$ & $0,35^{* * *}$ & $0,40 * * *$ \\
& $(0,0036)$ & $(0,0033)$ & $(0,0029)$ \\
\hline
\end{tabular}

Nota: $* \mathrm{p}<0,1 ; * * \mathrm{p}<0,05 ; * * * \mathrm{p}<0,01$. Individuos entre 18 y 65 años con ingresos laborales positivos.

Fuente: Elaboración propia con base en las encuestas del programa MESEP - DANE. 
Tabla 6a. Brecha bruta por componente. Descomposición de Oaxaca - Blinder.

\begin{tabular}{|c|c|c|c|}
\hline & 2004 & 2008 & 2012 \\
\hline \multirow[t]{2}{*}{ Brecha bruta } & $0,14 * * *$ & $0,12 * * *$ & $0,11 * * *$ \\
\hline & $(0,0033)$ & $(0,026)$ & $(0,0018)$ \\
\hline \multicolumn{4}{|l|}{ Efecto características } \\
\hline \multirow[t]{2}{*}{ Educación (en años) } & $-0,065 * * *$ & $-0,13 * * *$ & $-0,15 * * *$ \\
\hline & $(0,0021)$ & $(0,0016)$ & $(0,0010)$ \\
\hline \multirow[t]{2}{*}{ Edad } & $0,028 * * *$ & $0,0052 * * *$ & $-0,017 * * *$ \\
\hline & $(0,0017)$ & $(0,0010)$ & $(0,0011)$ \\
\hline \multirow[t]{2}{*}{ Edad cuadrado } & $-0,026 * * *$ & $-0,010 * * *$ & $0,0066^{* * *}$ \\
\hline & $(0,0013)$ & $(0,00083)$ & $(0,00090)$ \\
\hline \multirow[t]{2}{*}{ Privado } & $0,00087 * * *$ & $0,0062 * * *$ & $0,0015^{* * *}$ \\
\hline & $(0,00010)$ & $(0,00030)$ & $(0,000088)$ \\
\hline \multirow[t]{2}{*}{ Gobierno } & $0,00056^{* * *}$ & 0,000020 & $0,0012 * * *$ \\
\hline & $(0,00010)$ & $(0,000040)$ & $(0,000066)$ \\
\hline \multirow[t]{2}{*}{ Domestico } & $0,040 * * *$ & $-0,013 * * *$ & $0,0076^{* * *}$ \\
\hline & $(0,0019)$ & $(0,00033)$ & $(0,00019)$ \\
\hline \multirow[t]{2}{*}{ Cuenta propia } & $0,020 * * *$ & $0,040 * * *$ & $0,0088^{* * *}$ \\
\hline & $(0,00055)$ & $(0,00077)$ & $(0,00037)$ \\
\hline \multirow[t]{2}{*}{ Atlántica } & $-0,0086 * * *$ & $-0,0013 * *$ & $-0,0015^{* * *}$ \\
\hline & $(0,00062)$ & $(0,00044)$ & $(0,00010)$ \\
\hline \multirow[t]{2}{*}{ Central } & $0,10^{* * *}$ & $0,00072 * *$ & $-0,0075 * * *$ \\
\hline & $(0,00039)$ & $(0,00021)$ & $(0,00021)$ \\
\hline \multirow[t]{2}{*}{ Pacifica } & $0,018 * * *$ & $-0,016^{* * *}$ & $-0,020 * * *$ \\
\hline & $(0,00060)$ & $(0,00040)$ & $(0,00029)$ \\
\hline \multirow[t]{2}{*}{ Orinoquia } & $-0,0018 * * *$ & $0,0012 * * *$ & $-0,00087 * * *$ \\
\hline & $(0,0013)$ & $(0,00010)$ & $(0,000055)$ \\
\hline
\end{tabular}

Nota: ${ }^{*} \mathrm{p}<0,1 ; * * \mathrm{p}<0,05 ; * * * \mathrm{p}<0,01$. Individuos entre 18 y 65 años con ingresos laborales positivos.

Fuente: Elaboración propia con base en las encuestas del programa MESEP - DANE. 
Tabla 6b. Brecha bruta por componente. Descomposición de Oaxaca - Blinder.

\begin{tabular}{|c|c|c|c|}
\hline & 2004 & 2008 & 2012 \\
\hline \multirow[t]{2}{*}{ Brecha bruta } & $0,14 * * *$ & $0,12 * * *$ & $0,11 * * *$ \\
\hline & $(0,0033)$ & $(0,026)$ & $(0,0018)$ \\
\hline \multicolumn{4}{|l|}{ Efecto remuneración } \\
\hline \multirow[t]{2}{*}{ Educación (en años) } & $0,035^{* * *}$ & $0,058 * * *$ & $0,036^{* * *}$ \\
\hline & $(0,0052)$ & $(0,0040)$ & 0,0028807 \\
\hline \multirow[t]{2}{*}{ Edad } & 0,062 & $0,67 * * *$ & $0,68 * * *$ \\
\hline & $(0,056)$ & $(0,048)$ & $(0,033)$ \\
\hline \multirow[t]{2}{*}{ Edad cuadrado } & 0,026 & $-0,41 * * *$ & $-0,39 * * *$ \\
\hline & $(0,028)$ & $(0,025)$ & $(0,017)$ \\
\hline \multirow[t]{2}{*}{ Privado } & $0,016^{* * *}$ & $-0,074 * * *$ & $-0,0037^{*}$ \\
\hline & $(0,0034)$ & $(0,0029)$ & $(0,0019)$ \\
\hline \multirow[t]{2}{*}{ Gobierno } & $-0,013 * * *$ & $-0,018 * * *$ & $-0,0069 * * *$ \\
\hline & $(0,0011)$ & $(0,00071)$ & $(0,00032)$ \\
\hline \multirow[t]{2}{*}{ Domestico } & $-0,021 * * *$ & $-0,0092 * * *$ & $-0,0061 * * *$ \\
\hline & $(0,0022)$ & $(0,00086)$ & $(0,00075)$ \\
\hline \multirow[t]{2}{*}{ Cuenta propia } & $0,010^{* *}$ & $-0,12 * * *$ & $0,013 * *$ \\
\hline & $(0,0050)$ & $(0,0055)$ & $(0,0040)$ \\
\hline \multirow[t]{2}{*}{ Atlántica } & $-0,0089 * * *$ & $-0,027 * * *$ & $0,013 * * *$ \\
\hline & $(0,0013)$ & $(0,0010)$ & $(0,00091)$ \\
\hline \multirow[t]{2}{*}{ Central } & $-0,073 * * *$ & $-0,14 * * *$ & $0,0083 * *$ \\
\hline & $(0,0052)$ & $(0,0030)$ & $(0,0024)$ \\
\hline \multirow[t]{2}{*}{ Pacifica } & $-0,081 * * *$ & $-0,059 * * *$ & $-0,014 * * *$ \\
\hline & $(0,0029)$ & $(0,0015)$ & $(0,00099)$ \\
\hline \multirow[t]{2}{*}{ Orinoquia } & $-0,0055^{* * *}$ & $-0,0035 * * *$ & $0,0038 * * *$ \\
\hline & $(0,00039)$ & $(0,00034)$ & $(0,00020)$ \\
\hline \multirow[t]{2}{*}{ Constante } & $0,18 * * *$ & $0,38 * * *$ & $-0,045 * * *$ \\
\hline & $(0,031)$ & $(0,026)$ & $(0,018)$ \\
\hline
\end{tabular}

Nota: ${ }^{*} \mathrm{p}<0,1 ; * * \mathrm{p}<0,05 ; * * * \mathrm{p}<0,01$. Individuos entre 18 y 65 años con ingresos laborales positivos. Fuente: Elaboración propia con base en las encuestas del programa MESEP - DANE. 
Tabla 7a. Brecha bruta por componente. Descomposición de Oaxaca - Blinder con corrección por sesgo de selección.

\begin{tabular}{|c|c|c|c|}
\hline & 2004 & 2008 & 2012 \\
\hline \multirow[t]{2}{*}{ Brecha bruta } & $0,14 * * *$ & $0,12 * * *$ & $0,11 * * *$ \\
\hline & $(0,0033)$ & $(0,0026)$ & $(0,0018)$ \\
\hline \multicolumn{4}{|l|}{ Efecto características } \\
\hline \multirow[t]{2}{*}{ Educación (en años) } & $-0,046^{* * *}$ & $-0,091 * * *$ & $-0,12 * * *$ \\
\hline & $(0,0016)$ & $(0,0016)$ & $(0,0010)$ \\
\hline \multirow[t]{2}{*}{ Edad } & $-0,0030 * *$ & $-0,0041 * * *$ & $0,0025 * * *$ \\
\hline & $(0,00095)$ & $(0,00085)$ & $(0,00051)$ \\
\hline \multirow[t]{2}{*}{ Edad cuadrado } & $0,0080^{* * *}$ & $0,011 * * *$ & $-0,0015^{* * *}$ \\
\hline & $(0,0011)$ & $(0,0010)$ & $(0,00029)$ \\
\hline \multirow[t]{2}{*}{ Privado } & $0,0076^{* * *}$ & $0,00044 * *$ & $-0,0029 * * *$ \\
\hline & $(0,00056)$ & $(0,00018)$ & $(0,00017)$ \\
\hline \multirow[t]{2}{*}{ Gobierno } & $0,0058 * * *$ & $-0,000073$ & $0,0035 * * *$ \\
\hline & $(0,00034)$ & $(0,00014)$ & $(0,00016)$ \\
\hline \multirow[t]{2}{*}{ Domestico } & $0,011 * * *$ & $-0,012 * * *$ & $0,0068 * * *$ \\
\hline & $(0,0020)$ & $(0,00032)$ & $(0,00018)$ \\
\hline \multirow[t]{2}{*}{ Cuenta propia } & $0,011 * * *$ & $0,042 * * *$ & $0,010 * * *$ \\
\hline & $(0,00045)$ & $(0,00081)$ & $(0,00043)$ \\
\hline \multirow[t]{2}{*}{ Atlántica } & $-0,000055$ & $-0,00085^{* *}$ & $0,00048 * * *$ \\
\hline & $(0,00065)$ & $(0,00027)$ & $(0,000065)$ \\
\hline \multirow[t]{2}{*}{ Central } & $0,014 * * *$ & $0,00039 * *$ & $-0,019 * * *$ \\
\hline & $(0,00051)$ & $(0,00011)$ & $(0,00040)$ \\
\hline \multirow[t]{2}{*}{ Pacifica } & $0,029 * * *$ & $-0,019 * * *$ & $-0,017 * * *$ \\
\hline & $(0,00098)$ & $(0,00048)$ & $(0,00028)$ \\
\hline \multirow[t]{2}{*}{ Orinoquia } & $-0,0022 * * *$ & $0,00061 * * *$ & $-0,0025^{* * *}$ \\
\hline & $(0,00015)$ & $(0,000062)$ & $(0,00014)$ \\
\hline \multirow[t]{2}{*}{ Mills } & $-0,087 * * *$ & $-0,16^{* * *}$ & $-0,14 * * *$ \\
\hline & $(0,0024)$ & $(0,0041)$ & $(0,0033)$ \\
\hline
\end{tabular}

Nota: ${ }^{*} \mathrm{p}<0,1 ;{ }^{* *} \mathrm{p}<0,05 ;{ }^{* * *} \mathrm{p}<0,01$. Individuos entre 18 y 65 años con ingresos laborales positivos.

Fuente: Elaboración propia con base en las encuestas del programa MESEP - DANE. 
Tabla 7b. Brecha bruta por componente. Descomposición de Oaxaca - Blinder con corrección por sesgo de selección

\begin{tabular}{|c|c|c|c|}
\hline & 2004 & 2008 & 2012 \\
\hline \multirow[t]{2}{*}{ Brecha bruta } & $0,14 * * *$ & $0,12 * * *$ & $0,11 * * *$ \\
\hline & $(0,0033)$ & $(0,0026)$ & $(0,0018)$ \\
\hline \multicolumn{4}{|l|}{ Efecto remuneración } \\
\hline \multirow[t]{2}{*}{ Educación (en años) } & 0,0028 & $-0,012$ & $-0,11 * * *$ \\
\hline & $(0,017)$ & $(0,016)$ & $(0,0083)$ \\
\hline \multirow[t]{2}{*}{ Edad } & $-0,18^{*}$ & 0,18 & $-1,28 * * *$ \\
\hline & $(0,11)$ & $(0,12)$ & $(0,10)$ \\
\hline \multirow[t]{2}{*}{ Edad cuadrado } & $0,12 *$ & $-0,19 * *$ & $0,53 * * *$ \\
\hline & $(0,050)$ & $(0,061)$ & $(0,052)$ \\
\hline \multirow[t]{2}{*}{ Privado } & $0,023 * * *$ & $-0,066^{* * *}$ & $0,046 * * *$ \\
\hline & $(0,0057)$ & $(0,0043)$ & $(0,0033)$ \\
\hline \multirow[t]{2}{*}{ Gobierno } & $-0,011 * * *$ & $-0,015 * * *$ & 0,00019 \\
\hline & $(0,0015)$ & $(0,0010)$ & $(0,00049)$ \\
\hline \multirow[t]{2}{*}{ Domestico } & $-0,019 * * *$ & $-0,0094 * * *$ & $-0,0031 * * *$ \\
\hline & $(0,0025)$ & $(0,00086)$ & $(0,00077)$ \\
\hline \multirow[t]{2}{*}{ Cuenta propia } & $0,019 * *$ & $-0,12 * * *$ & $-0,015 * * *$ \\
\hline & $(0,0059)$ & $(0,0055)$ & $(0,0043)$ \\
\hline \multirow[t]{2}{*}{ Atlántica } & $-0,0082 * * *$ & $-0,022 * * *$ & $0,038 * * *$ \\
\hline & $(0,0014)$ & $(0,0015)$ & $(0,0016)$ \\
\hline \multirow[t]{2}{*}{ Central } & $-0,076^{* * *}$ & $-0,13 * * *$ & $0,076 * * *$ \\
\hline & $(0,0056)$ & $(0,0034)$ & $(0,0043)$ \\
\hline \multirow[t]{2}{*}{ Pacifica } & $-0,086^{* * *}$ & $-0,063 * * *$ & $-0,0076^{* * *}$ \\
\hline & $(0,0045)$ & $(0,0017)$ & $(0,0010)$ \\
\hline \multirow[t]{2}{*}{ Orinoquia } & $-0,0053 * * *$ & $-0,0029 * * *$ & $0,0090 * * *$ \\
\hline & $(0,00039)$ & $(0,00036)$ & $(0,00035)$ \\
\hline \multirow[t]{2}{*}{ Mills } & $-0,20$ & $-0,45 * * *$ & $-1,90 * * *$ \\
\hline & $(0,12)$ & $(0,12)$ & $(0,10)$ \\
\hline \multirow[t]{2}{*}{ Constante } & $0,62 * *$ & $1,27 * * *$ & $3,02 * * *$ \\
\hline & $(0,19)$ & $(0,19)$ & $(0,16)$ \\
\hline
\end{tabular}

Nota: $* \mathrm{p}<0,1 ; * * \mathrm{p}<0,05 ; * * * \mathrm{p}<0,01$. Individuos entre 18 y 65 años con ingresos laborales positivos. Fuente: Elaboración propia con base en las encuestas del programa MESEP - DANE. 
Tabla 8a. Brecha bruta, efecto características y efecto remuneración. Metodología Melly (2005).

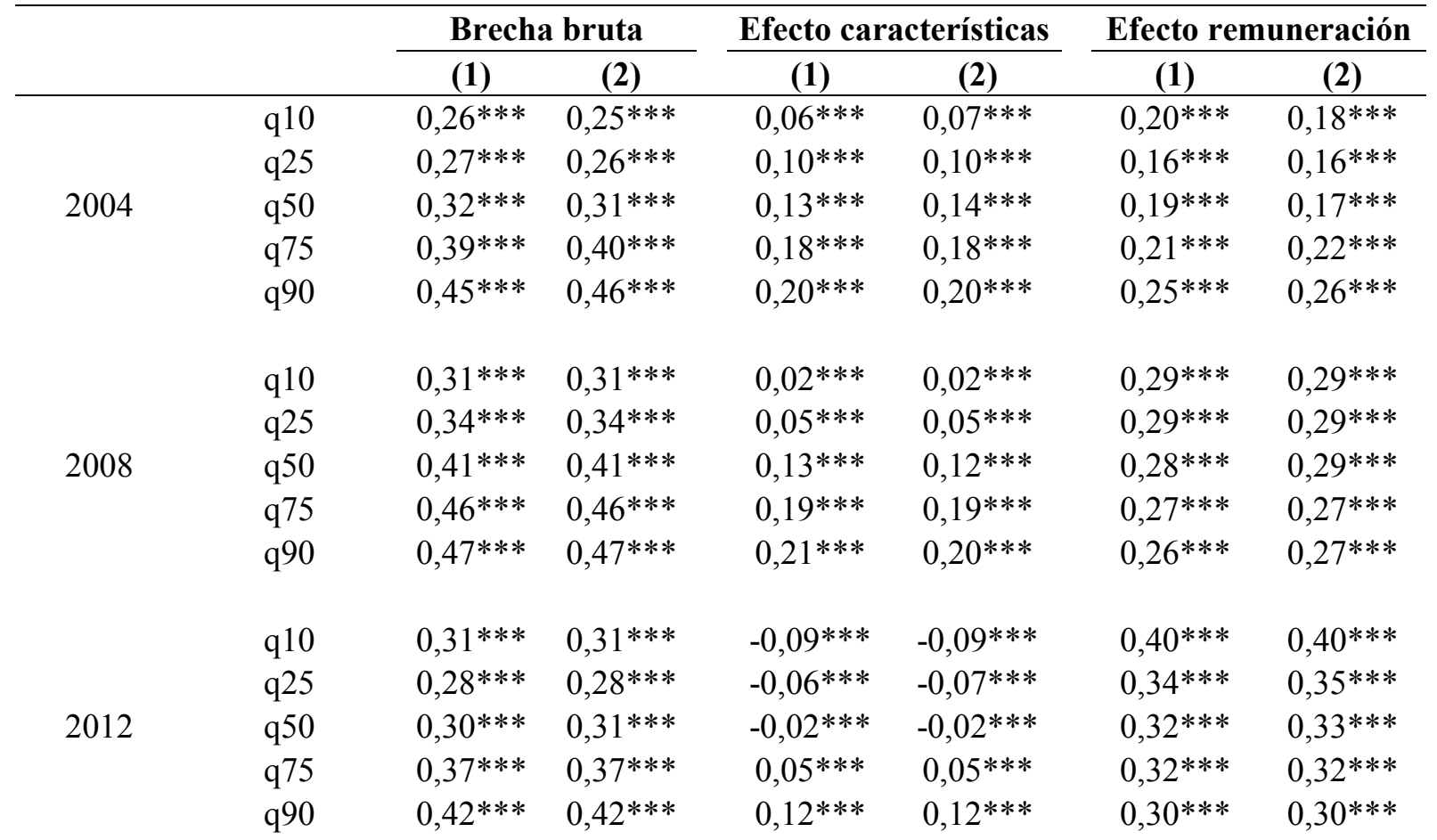

Controles:

Educación, edad y

ocupación

Si $\quad$ Si $\quad$ Si $\quad$ Si

$\mathrm{Si}$

$\mathrm{Si}$

$\mathrm{Si}$

Región

No Si

No

$\mathrm{Si}$

No

$\mathrm{Si}$

Nota: ${ }^{*} \mathrm{p}<0,1 ; * * \mathrm{p}<0,05 ; * * * \mathrm{p}<0,01$. Individuos entre 18 y 65 años con ingresos laborales positivos.

Fuente: Elaboración propia con base en las encuestas del programa MESEP - DANE.

Tabla 8b. Rango intercuantílico $(90$ - 10), brecha bruta, efecto características y efecto remuneración. Metodología Melly (2005).

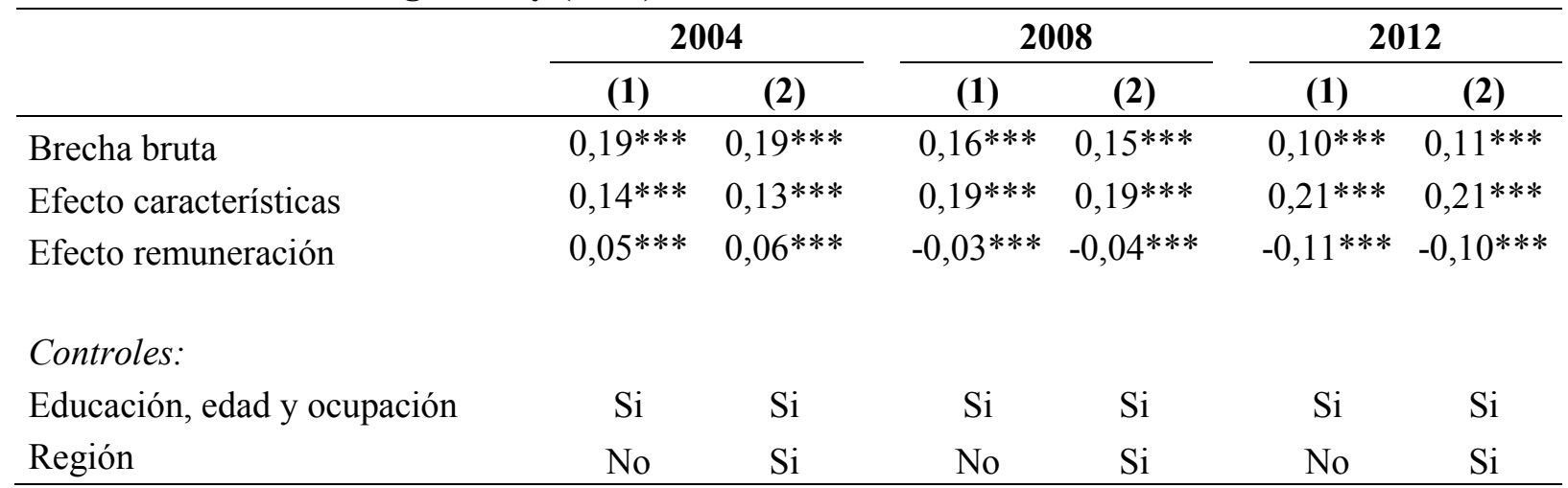

Nota: $* \mathrm{p}<0,1 ; * * \mathrm{p}<0,05 ; * * \mathrm{p}<0,01$. Individuos entre 18 y 65 años con ingresos laborales positivos.

Fuente: Elaboración propia con base en las encuestas del programa MESEP - DANE. 
Tabla 9a. Brecha bruta, efecto características y efecto remuneración. Metodología Melly (2005) y Buchinsky (1998) con corrección por sesgo de selección.

\begin{tabular}{|c|c|c|c|c|c|c|c|}
\hline & & \multicolumn{2}{|c|}{ Brecha bruta } & \multicolumn{2}{|c|}{ Efecto características } & \multicolumn{2}{|c|}{ Efecto remuneración } \\
\hline & & (1) & (2) & (1) & (2) & (1) & (2) \\
\hline \multirow{5}{*}{2004} & q10 & $0,26^{* * *}$ & $0,25 * * *$ & $0,12 * * *$ & $0,05 * * *$ & $0,14 * * *$ & $0,20 * * *$ \\
\hline & $\mathrm{q} 25$ & $0,27 * * *$ & $0,26 * * *$ & $0,14 * * *$ & $0,08 * * *$ & $0,13 * * *$ & $0,18 * * *$ \\
\hline & $\mathrm{q} 50$ & $0,32 * * *$ & $0,31 * * *$ & $0,16 * * *$ & $0,10 * * *$ & $0,16 * * *$ & $0,21 * * *$ \\
\hline & q75 & $0,39 * * *$ & $0,40 * * *$ & $0,18 * * *$ & $0,14 * * *$ & $0,21 * * *$ & $0,26 * * *$ \\
\hline & q90 & $0,45^{* * *}$ & $0,46 * * *$ & $0,19 * * *$ & $0,15 * * *$ & $0,26 * * *$ & $0,31 * * *$ \\
\hline \multirow{5}{*}{2008} & q10 & $0,31 * * *$ & $0,31 * * *$ & $-0,04 * * *$ & $-0,06 * * *$ & $0,35 * * *$ & $0,37 * * *$ \\
\hline & $\mathrm{q} 25$ & $0,34 * * *$ & $0,34 * * *$ & $0,01 * * *$ & $-0,02 * * *$ & $0,31 * * *$ & $0,36^{* * *}$ \\
\hline & q50 & $0,41 * * *$ & $0,41 * * *$ & $0,09 * * *$ & $0,04 * * *$ & $0,32 * * *$ & $0,37 * * *$ \\
\hline & $\mathrm{q} 75$ & $0,46 * * *$ & $0,46 * * *$ & $0,14 * * *$ & $0,09 * * *$ & $0,32 * * *$ & $0,37 * * *$ \\
\hline & q90 & $0,47 * * *$ & $0,47 * * *$ & $0,15 * * *$ & $0,08 * * *$ & $0,32 * * *$ & $0,39 * * *$ \\
\hline \multirow{5}{*}{2012} & q10 & $0,31 * * *$ & $0,31 * * *$ & $-0,06 * * *$ & $-0,15 * * *$ & $0,37 * * *$ & $0,46 * * *$ \\
\hline & $\mathrm{q} 25$ & $0,28 * * *$ & $0,28 * * *$ & $-0,04 * * *$ & $-0,13 * * *$ & $0,32 * * *$ & $0,41 * * *$ \\
\hline & $\mathrm{q} 50$ & $0,30 * * *$ & $0,31 * * *$ & $-0,01 * * *$ & $-0,09 * * *$ & $0,31 * * *$ & $0,40 * * *$ \\
\hline & $\mathrm{q} 75$ & $0,37 * * *$ & $0,37 * * *$ & $0,06 * * *$ & $-0,03 * * *$ & $0,31 * * *$ & $0,40 * * *$ \\
\hline & q90 & $0,42 * * *$ & $0,42 * * *$ & $0,12 * * *$ & $0,03 * * *$ & $0,30 * * *$ & $0,39 * * *$ \\
\hline
\end{tabular}

Controles:

Educación, edad y

ocupación

$\begin{array}{lll}\mathrm{Si} & \mathrm{Si} & \mathrm{Si} \\ \mathrm{No} & \mathrm{Si} & \mathrm{No}\end{array}$

$\mathrm{Si}$

$\mathrm{Si}$

No

$\mathrm{Si}$

Nota: ${ }^{*} \mathrm{p}<0,1 ; * * \mathrm{p}<0,05 ; * * * \mathrm{p}<0,01$. Individuos entre 18 y 65 años con ingresos laborales positivos.

Fuente: Elaboración propia con base en las encuestas del programa MESEP - DANE.

Tabla 9b. Rango intercuantílico (90 - 10), brecha bruta, efecto características y efecto remuneración. Metodología Melly (2005) y Buchinsky (1998) con corrección por sesgo de selección.

\begin{tabular}{|c|c|c|c|c|c|c|}
\hline & \multicolumn{2}{|c|}{2004} & \multicolumn{2}{|c|}{2008} & \multicolumn{2}{|c|}{2012} \\
\hline & (1) & (2) & (1) & (2) & (1) & (2) \\
\hline Brecha bruta & $0,20 * * *$ & $0,19 * * *$ & $0,16^{* * *}$ & $0,15 * * *$ & $0,10 * * *$ & $0,07 * * *$ \\
\hline Efecto características & $0,11 * * *$ & $0,10 * * *$ & $0,19 * * *$ & $0,14 * * *$ & $0,18^{* * *}$ & $0,23 * * *$ \\
\hline Efecto remuneración & $0,09 * * *$ & $0,09 * * *$ & $-0,03 * * *$ & $0,01 * * *$ & $-0,08 * * *$ & $-0,16 * * *$ \\
\hline \multicolumn{7}{|l|}{ Controles: } \\
\hline Educación, edad y ocupación & $\mathrm{Si}$ & $\mathrm{Si}$ & $\mathrm{Si}$ & $\mathrm{Si}$ & $\mathrm{Si}$ & $\mathrm{Si}$ \\
\hline Región & No & $\mathrm{Si}$ & No & $\mathrm{Si}$ & No & $\mathrm{Si}$ \\
\hline
\end{tabular}

Nota: ${ }^{*} \mathrm{p}<0,1 ; * * \mathrm{p}<0,05 ; * * * \mathrm{p}<0,01$. Individuos entre 18 y 65 años con ingresos laborales positivos.

Fuente: Elaboración propia con base en las encuestas del programa MESEP - DANE. 